\title{
تقنين مقياس المرونة العقلية لدى طلاب الجامعة
}

\author{
إعداد \\ زينب محمد أمين محمد إد \\ مدرس مساعد بقسم علم النفس التريوي \\ كلية التربية بأسوان
}




\section{ملخص البحث:}

هدف البحث إلى تقنين مقياس المرونـة العقلية لدى طـلاب الجامعـة لتزويد

الباحثين في مجال علم النفس التربوي بمعايير مناسبة لقياس المرونـة العقلية لدى

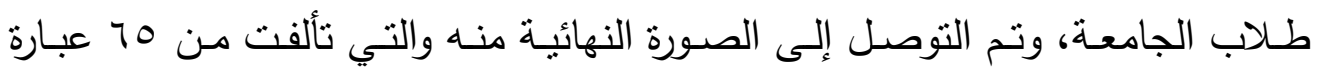

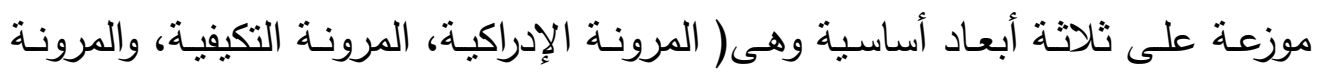

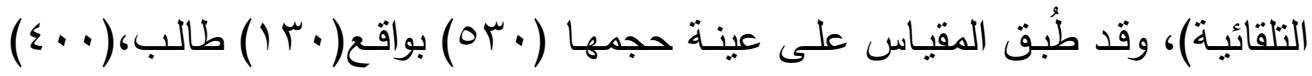
طالبة من طلاب كليتي التربية والتربية النوعية ويتراوح العمر الزمني لأفراد العينة بين

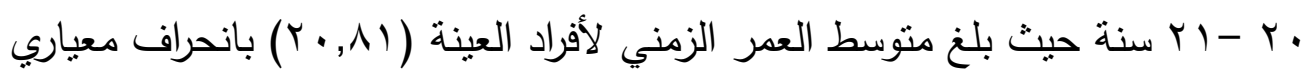

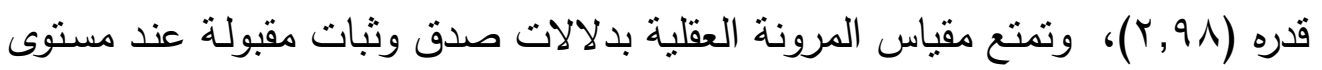
| , • - 0 • , •بين متوسطات درجات مجموعتي الطلاب مرتفعي ومنخفضسي المرونة

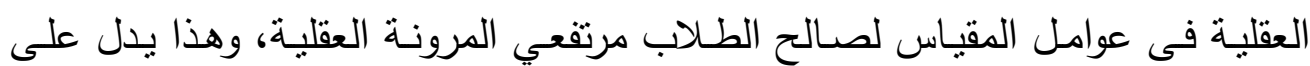
صـدق عوامـل المقيـاس فـى قيـاس مـا وضـعت لقياســ(المرونة العقليـة)، وتراوحـت

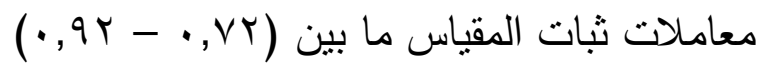

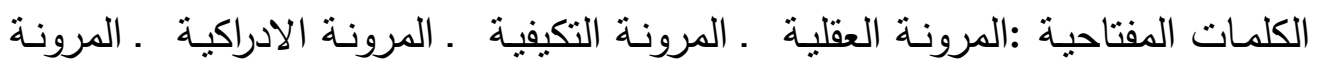
التلقائية 


\section{Abstract:}

The research aims to regulate the mental flexibility measure of university students to provide researchers in the field of Educational Psychology with suitable standards for measuring mental flexibility among university students. It was reached the final image of it, which consisted of 65 statements, distributed on three basic dimensions of a (cognitive flexibility, adaptive flexibility and automatic flexibility). The scale was applied to a sample of 530; 130 male students 400 female students, from the faculties of education and qualitative education students Lifespan for the sample members ranged between 20-21 years old with a lifespan average (20.81), with a standard deviation (98.2). The mental flexibility measure has acceptable credibility and validity indications at $01,0-0.50$ between the mean scores of the two groups of students This means that the scale factors that distinguish distinctively, clearly and significantly between high and low students ' mental flexibility. This shows the scale factors credibility in the measure was developed to measure it (mental flexibility). The coefficients of the scale validity ranged between (72.0 to 92.0).

Key words: mental flexibility- cognitive flexibility - adaptive flexibility

Automatic flexibility. 
تعثبر المرونة صفة ملازمة للحياة وهى قوة كامنة خلقها الله تعالى فى الإنسان، ولا يُمكن أن نتحول إلى ميزة إلا إذا قام الفرد بتفعيلها بالتجربة والممارسة. ويبدأ ذلك عندما ينظر إلى الأمر الواحد بمناظير مختلفة، ويعترف بوجود وجهات نظر بدلاً من وجهة النظر الوحيدة والقطعية، فيُغير فى مواقفه وردود أفعاله وعاداته الموروثة، وعندها يستطيع أن يحول الغضب إلى صبر، والكلالة إلى الفعالية، والعجز والتوكل والسلبية إلى المبادرة والنشاط وتحمل المسؤولية الذاتية.

فالمرونة العقلية Mental Flexibility تُعد" أحد المتطلبات الضرورية لدى الفرد في مواجة المواقف المتباينة التي تواجهه وما يترتب عليها من متغيرات مفاجئة، وعليه

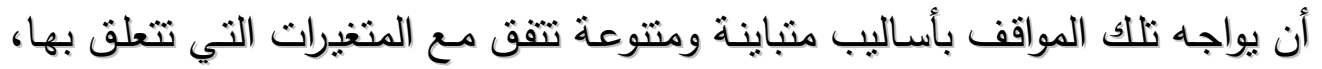

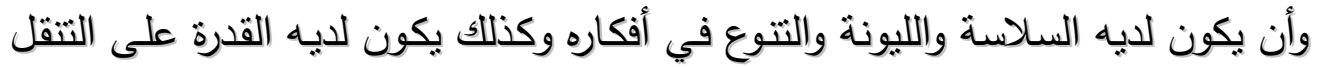

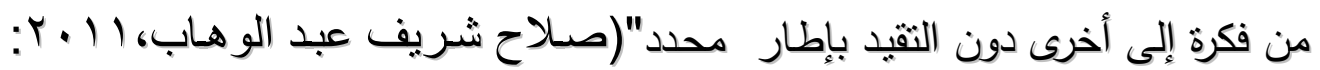

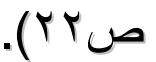

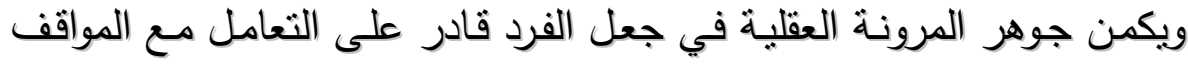
المختلفة بطرق مختلفة، وخاصـة في الاستجابة بفعالية مـع الأوضـاع الجديدة المعقدة

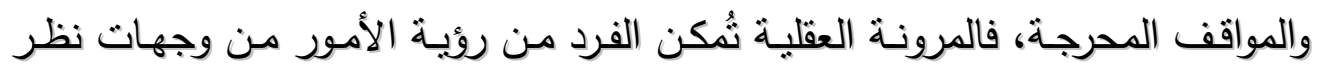

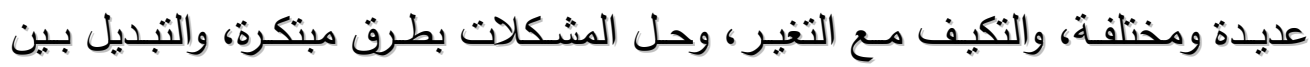

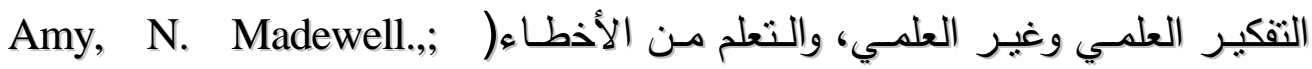
.(Elisabeth, Ponce-Garcia., 2016 فكثير من الطلاب يواجهوا المواقف الصعبة التي لا تحسم دوماً وفقاً لرغباتهم وأهدافهم، لذلك الطريقة الأفضل لمواجهة الظروف والتغيرات غير المرغوب فيها هي امتلاك الطلاب للمرونـة العقلية والتي تجعلـه قادر على التكيف مـع المتغيرات التي لهي 
تواجهه دوماً والتأقلم مع كل ما هو جديد، فالأشخاص الذين يفشلون في التكيف مـع التغيرات هم أكثر عرضة لمواجهة الأوقات العصيبة(Louis, H.,; Craig, Z., 2007).

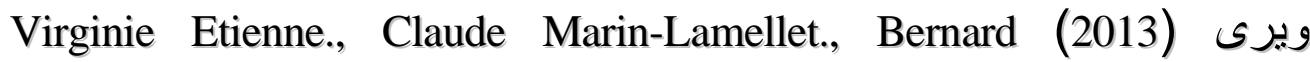
أن الطلاب وخاصة طلاب الجامعة لابد من تفعيل الوظائف المعرفية ووظائف الإدراك الحسي من خلال المرونة العقلية والتي تسمح للطالب بتكيف سلوكه لإنه مع الأوضاع المتغيرة والأوضاع الجديدة، فالتحول الذهني من استراتيجية إلى أخرى يجعل الطالب منتوع الأفكار ومبدع في الحلول وهذا هو جوهر مفهوم المرونة.

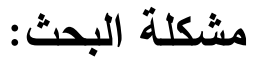

فلدى كل فرد درجة من التصلب الفكرى، وذلك يعود إلى أمرين: الأول، أن من

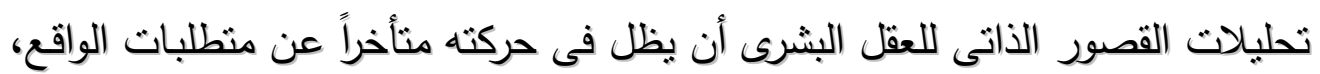

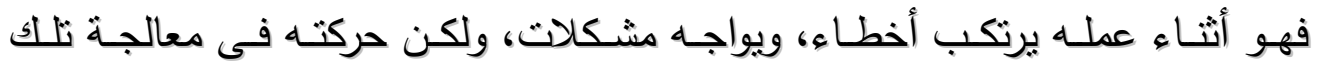

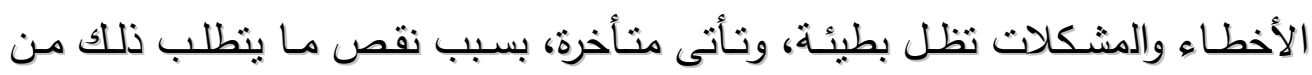

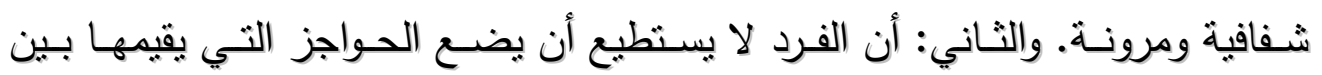
التصلب الممدوح الذى يتمثل في استنقرار العقائد والمبادئ والمفـاهيم الكبرى، وبين التصلب المذموم الذى يتمثل في نقص المرونـة العقلية، وفى اعتـاق بعض المفاهيم الخاطئة التي تجعل المرهء فاقداً الرشد الفكري(Eagle, N., 2008).

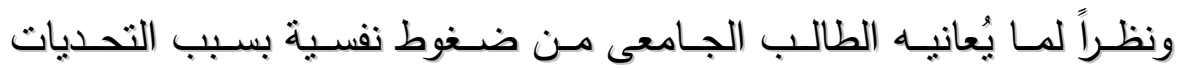

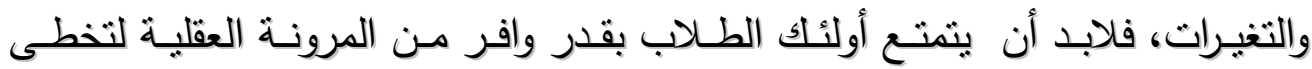
الأزمات التى تعصف بهم، فالمرونـة العقلية تعثبر قوة دافعة لسلوك الإنسان فى تكيفه

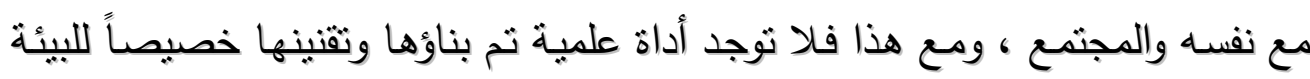
المصرية وطلاب الجامعة ، لذلك يبادر البحث الحالى بتقنين مقياس المرونـة العقلية لضمان صلاحيتها وموثوقيتها للنطبيق فى البيئة المصرية. 
يحاول هذا البحث الوصول إلى انجاز الأهداف الرئيسية التالية: - بناء مقياس للمرونة العقلية لدى طلاب الجامعة.

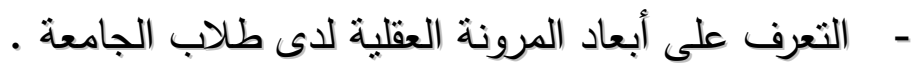
- التعرف على الخصائص السيكومترية لمقياس المرونة العقلية لدى طلاب

$$
\text { مصطلحات البحث: الجامعة. }
$$

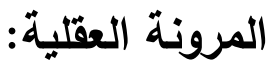

يثير مفهوم المرونـة العقلية Mental Flexibility إلى السبب الحقبقى الكـامن وراء ذكـاء وتفوق وتمبـز الأثـخاص، لأنهـا المولـد الفعلى للأفكـار والحلـول

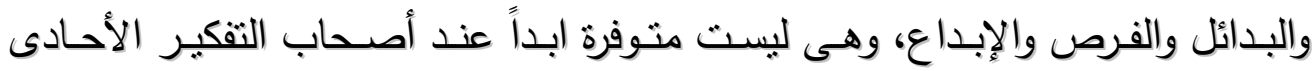

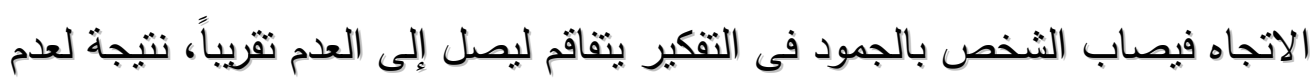
امتلاك الشخص لهذه القدرة العقلية.

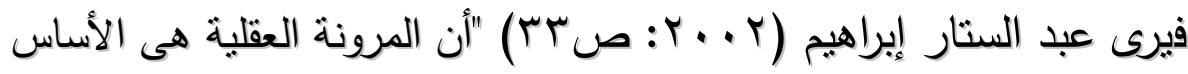

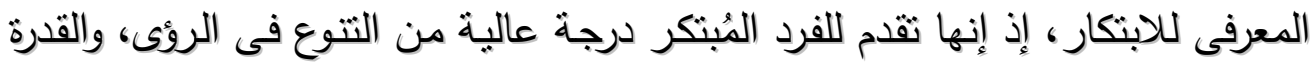

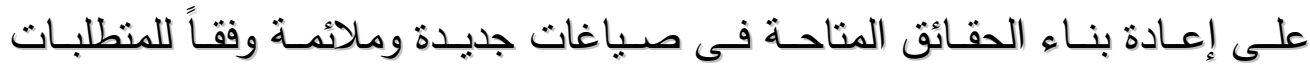

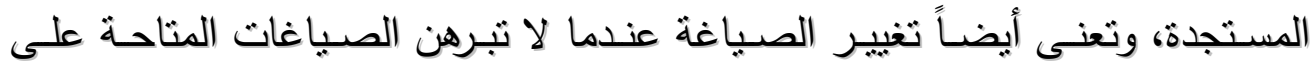

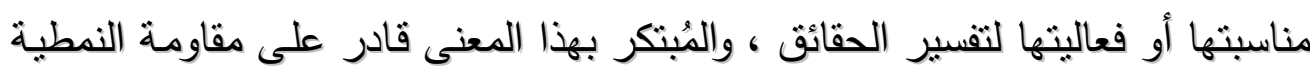

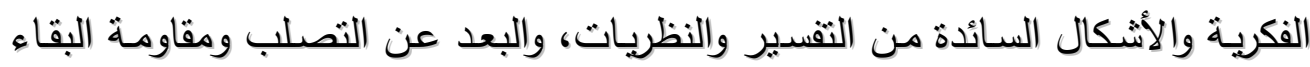
ضمن إطار النمط التقلبدي من حل المشكلات".

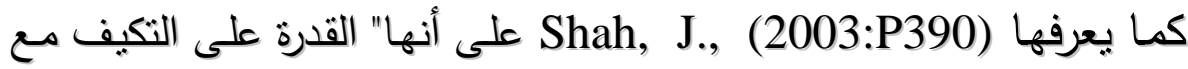
الأحداث والمواقف الضاغطة، فهى عملية مستمرة يُظهر الفرد من خلالها سلوكاً نكيفياً الهياً إيجابياً في مواجهة المشكلات". 
وأثنار كل من Dibbets, P., ; Jolles, J.,(2006:P62) إلى المرونة العقلية على أنها" قدرة الفرد على سرعة إنتاج الأفكار وتتوعها وتحول وجهته الذهنية بما يتتاسب مع الموقف".

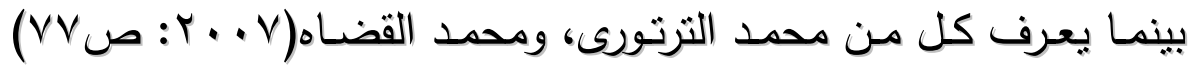

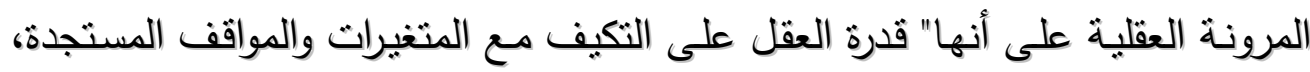
والانتقال من زاوية جامدة إلى زاوية متحررة تقتضيها المواجهة".

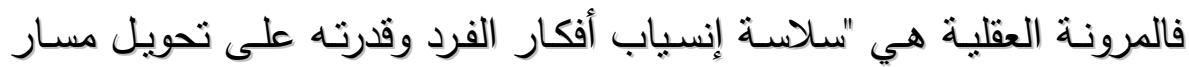
تفكيره، طبقاً لتغير مثيرات الموقف الذى يواجهه"(Ran, R., 2009:P 22).

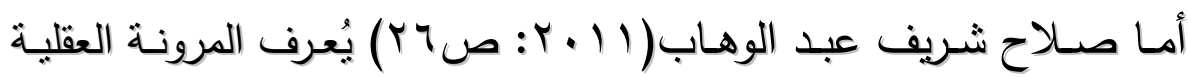

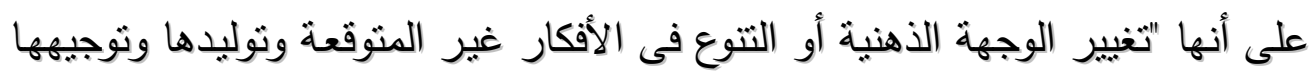

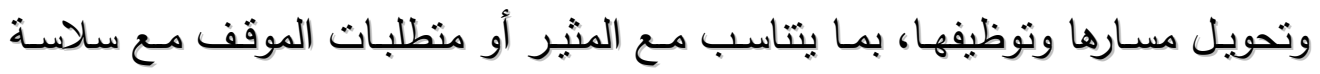
التفكير وعدم الجمود الفكري".

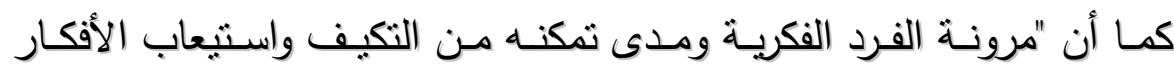
الجديدة طبقاً للظروف المتغيرة ووجهات النظر المختلفة يعتبر مرونـة عقلية" وهذا ما كابه أنشار به كل من:P145:P1lliam, S., ; Lisa Iguchi., 2013:).

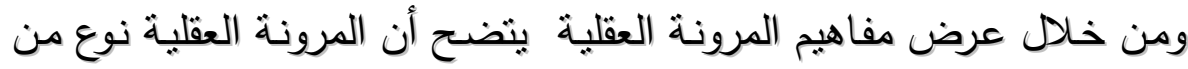

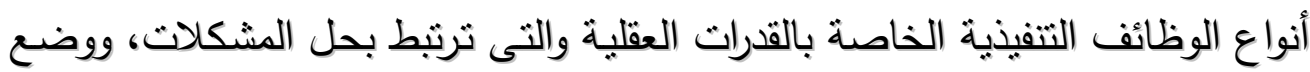

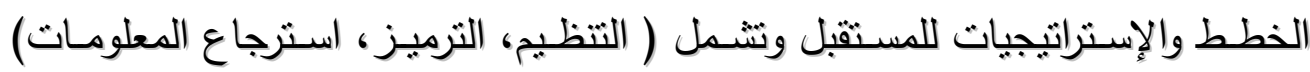
ومعالجة المعلومات بسرعة، فهى بذلك تتعلق بقدرة الفرد على مواجهة المواقف المختلفة

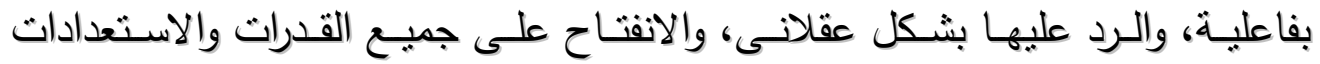
لتطويعها وملائمتها للظروف المستجدة، وإقامة علاقات طيبة مع الآخرين، أساسها الود والاحترام المتبادل وتقبل الآخرين.

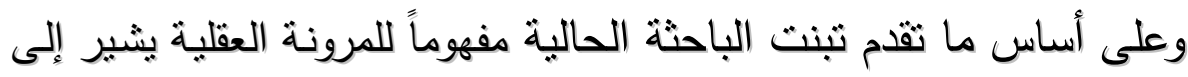
" قدرة ورغبة الفرد فى التكيف مـع الواقع، وتغيير موقفه العقلي تجاه المثيرات الجديدة

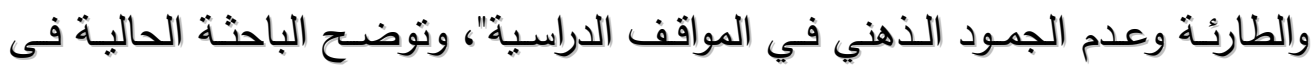
الثكل( (1) موقع المرونة العقلية من بين المهارة والاتجاه. 
زينب محمد أمين محمد

تقنين مقياس المرونة العقلية لدى طلاب الجامعة

شكل ( ) يوضح المرونة العقلية
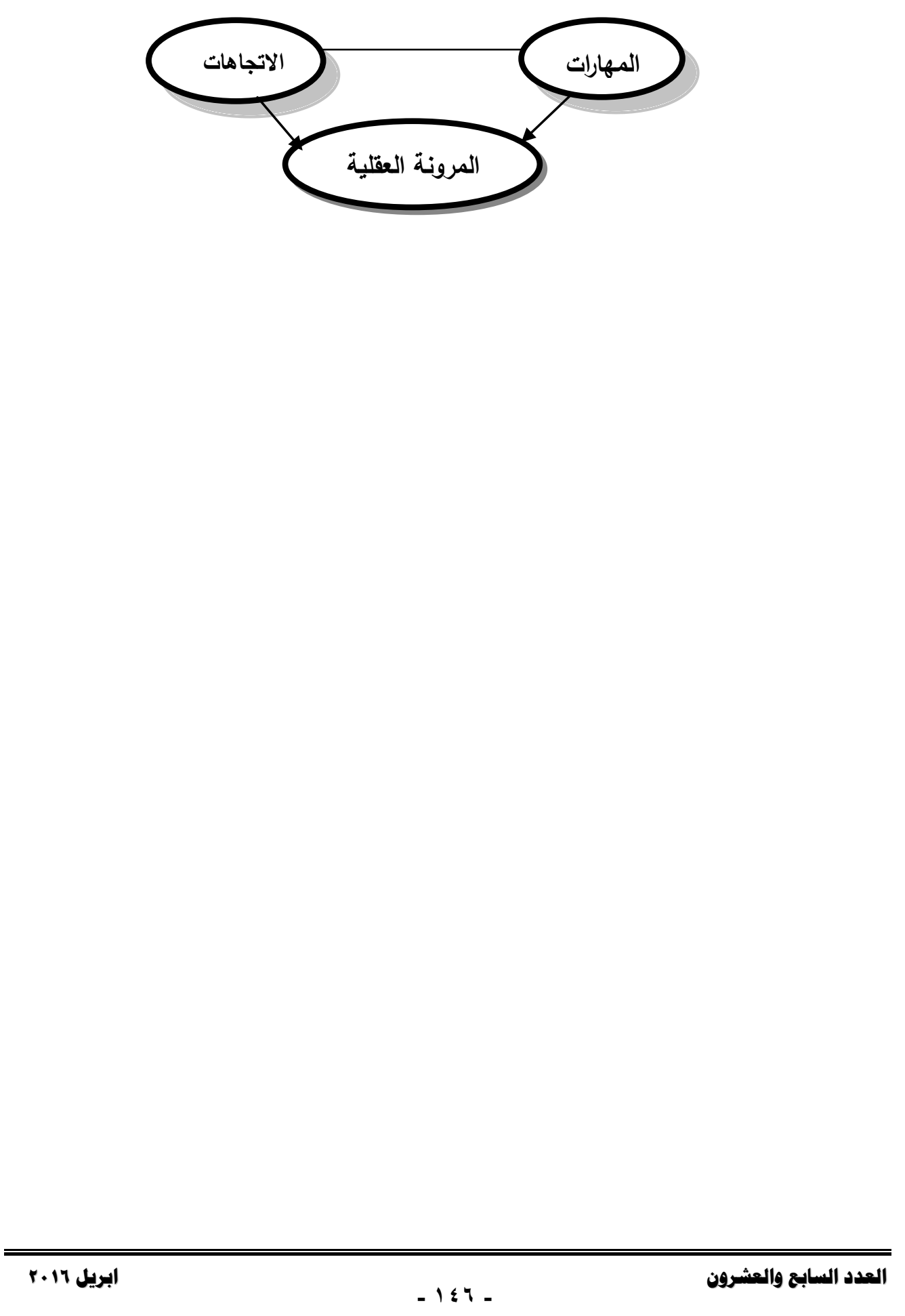
الإطار النظري: - (النظي

"تعتبر المرونـة مـن أهم العوامل المكونـة للقدرة على التفكير الإبنتـارى، وهى

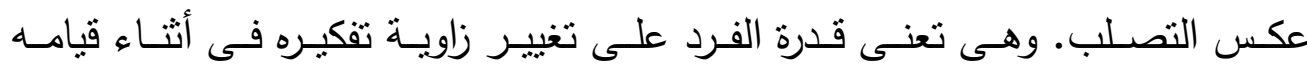

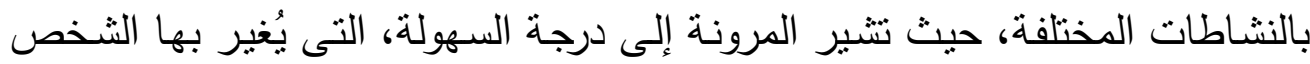
موقفاً ما أو وجهة عقلية معينة، وقد اهتم كثير من علماء النفس اهتماماً كبيراً، بإجراء العديد من الدراسات عن مفهوم المرونة، وعلاقتها بالعديد من المتغيرات وذلك لأهميتها

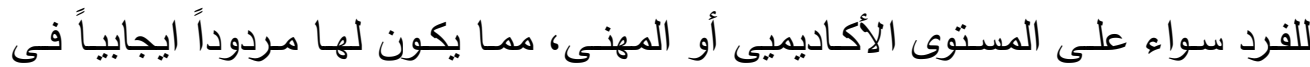

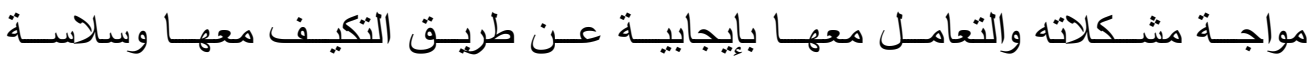

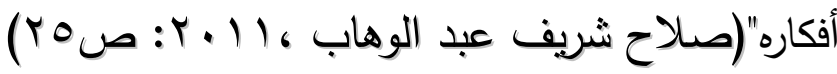

$$
\begin{aligned}
& \text { أبعاد المرونة العقلية: }
\end{aligned}
$$

تتطلب المرونة العقلية تغيرات فى سلوك الثخص وتفكيره واتجاهاته، وتفرض عليه هذه التغيرات أن يكون على درجة عالية من المطاوعة والقابلية للتغير، فإذا عجز

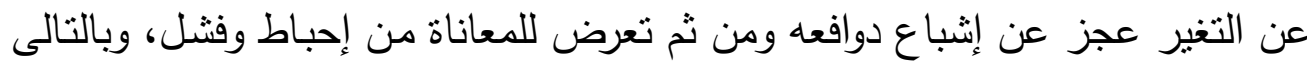
اتفق العلماء على أن المرونة العقلية تتكون من بعدين رئيسيين هما:

\section{Adaptive Flexibility المرونة التكيفية}

" فالمرونة التكيفية قدرة يمتلكها الفرد لتُكنه من إعادة صياغة الخبرة فى أنماط جديدة عن طريق تقديم أكبر عدد ممكن من البدائل لإعادة صياغة الخبرة بأساليب متتوعة وملائمة للموقف الذى يواجهه الفرد بحيث تتميز هذه الأنماط الجديدة الناتجة بالحداثة بالنسبة للفرد نفسه وللمجتمع الذى يعيش فيه، وهذه القدرة يمكن التدرب عليها

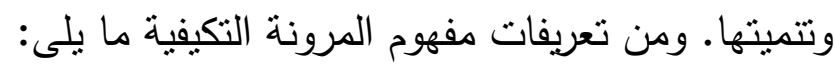
- قدرة الفرد على تغيير الاتجاه الذهنى بسرعة لمواجهه المواقف الجديدة والمشكلات المتغيرة، وتسهح هذه القدرة فى توفير العديد من الحلول الممكنة للمشاكل بشكل

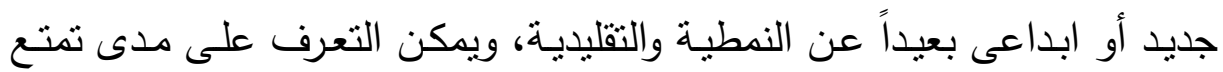


الثخص بهذه القدرة عن طريق الاختبارات التى تقدم للفرد، ثم تطلب منه إيجاد حلول منتوعة لها، رغم توفر بعض الحلول التقليدية المعروفة للمشكلة، إلا أنها تعتبر مرفوضة، لأن ما هو مطلوب فى مثل هذا الموقف هو التتوع.

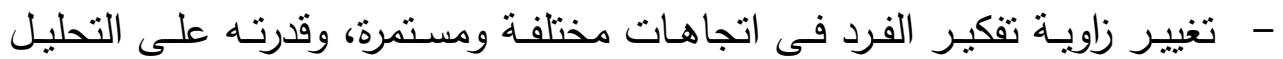

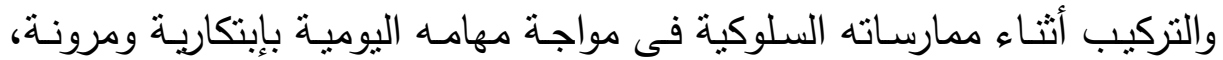
والتغيير فى الحلول الممكنة للمشكلات التى يتعرض لها الثخص فى البيئة التى يعيش فيها، منل اقتراح العديد من الحلول لروية قصيرة.

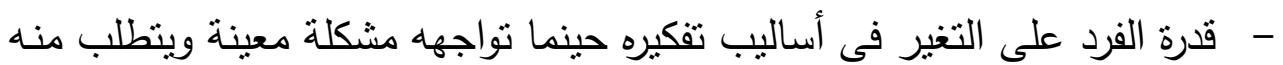
حلها، ولا يأتى ذلك الإ عن طريق التغيير فى وجهته الذهنية دون التقيد بإطار معين" ويمكن النظـر إلى الوجهـه الذهنيـة باعتبارهـا الطرف الموجب للتكيف العقلي، فالمرونة (التكيف العقلي) عكس التصلب الذهني. - تغيير الفرد لرويته ووجهته الذهنية عند مواجهة متغيرات جديدة ومفاجئة حول

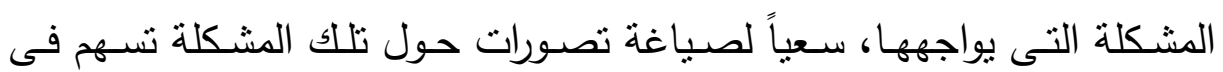
حلها، مثنل مواجهة الفـرد لمشكلات رياضية تتطلب إعـادة صـياغة للمشكلة للوصول إلى حلول لها.

- قدرة الفرد على التكيف مـع المشكلات التى تواجهه، من خـلال تغيير وجهته

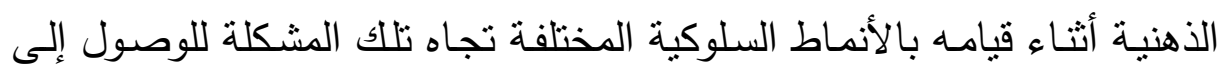
الحل المناسب لها، وأن يكون متحرراً من الجمود الفكرى خـلال اقتراحه لحلول المشكلة، غير مقيد بإطار فكرى واحد ومحدد.

\section{Spontaneous Flexibility المرونة التتائية}

يُشتير مفهوم المرونـة التلقائية إلى قدرة تُكن الفرد من إنتاج أكبر عدد من

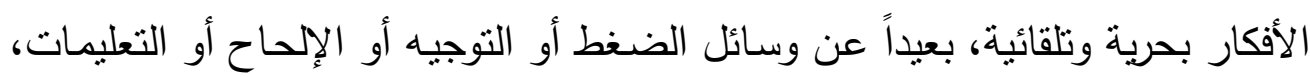
ويتطلب الاختيـار الذى يقيس هذه القدرة مـن الفرد أن يتجـول بفكره بكل حربـة في

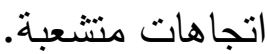




\section{ومن تعريفات المرونة التلقائية ما يلى:}

- القدرة على إنتاج أكبر قدر ممكن من الأفكار المتنوعة حول موثق ما، مثل الاسـتخدامات غيـر التقليديـة لأثـياء يسـتخدمها الفـرد فـى حياتـهـ البومبة. - قدرة الفرد على الانتقال من فكرة إلى أخرى حول مشكلة ما، ومدى نتوعه فى الأفكار والحلول التى أنتجها دون التقبد بإطار معين حول الموقف أو المشكلة التى تواجهه. - قدرة الفرد على السرعة فى إنتاج أكبر عدد ممكن من الأفكار المتنوعة تجاه موقف معين، وتقاس المرونة التلقائية فى مدى سرعة إنتاج الأفكار من جانب الفرد بناء على استعداده الانفعالى وتوجهه العقلى.

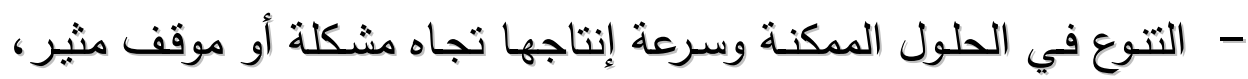
ويتمبز الفرد بتلقائية فى إصدار الأفكار . - قـدرة الفـرد على إنتـاج العديـد مـن الأفكـار مسـتخدماً إمكاناتـه العقليـة والانفعالية وفى وقت قصير تجاه موقف معين". (Mc Nulty., et al ,2010) ؛ (Ran,R., 2009) ؛ (Lisa Iguchi, William,

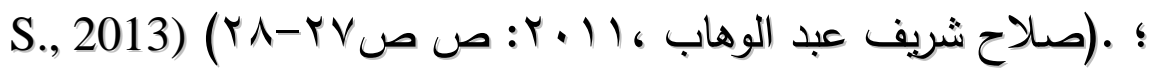
ومن خلال عرض أبعاد المرونة العقلية ( المرونـة التكيفية والمرونـة التلقائية) ومفاهيم كل منها، توضح الباحثة الحالية أبعاد المرونة العقلية كالتالى:

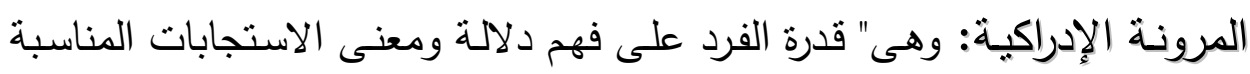
للموقف والتفكير بمرونة لتطوير الاستجابات البديلة وتعديل واستبدال الاستجابات

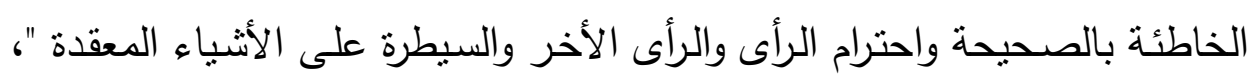
فتعتبر المرونة الإدراكية عنصر من عناصر السلطة التتفيذية، وشكل من أشكال الإشراف والمراقبة على العمليات المعرفية المطلوبة لنتفيذ سلوك معين، أو السيطرة 
على أثشياء معقدة وذلك باستخدام التمثيلات الداخليـة والتـى تعدل على توجيـة

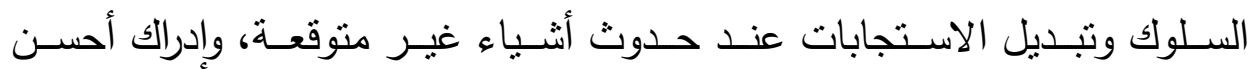
Virginie Etienne,; Claude الاستجابات المتوافقة مسع الموقف، ويؤكد Marin-Lamellet,; Bernard Laurent(2013) تعتبر بعد مهم من أبعاد المرونة العقلية حيث أن السائقين الذين لا يمنلكون مرونة إدراكيـة عاليـة لا يستطيعون التصـرف في المواقف المفاجئة، فالمرونـة الإدراكيـة مرتبطة بالنشاط العصبى والسيطرة الدماغية والجمود الذهني في المواقف. المرونـة التكيفيـة: وهـى " قدرة الفرد الايجابيـة على إنتقاء الاستجابات الملائمـة

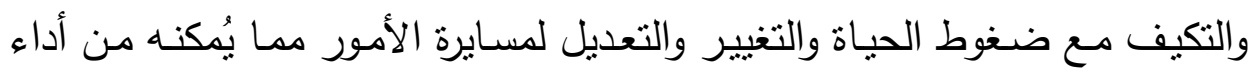

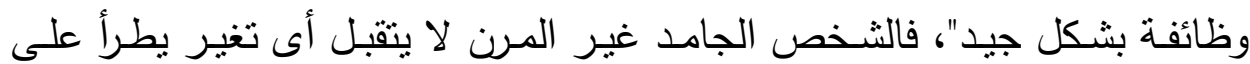

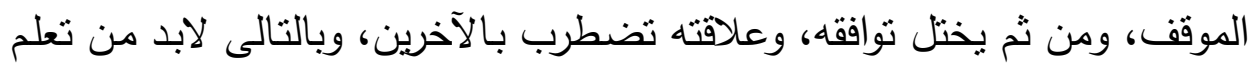

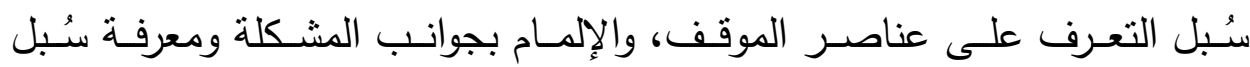

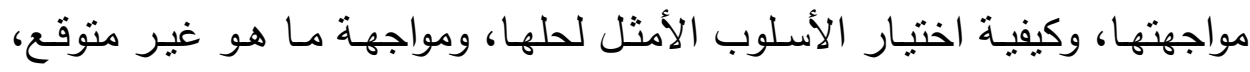

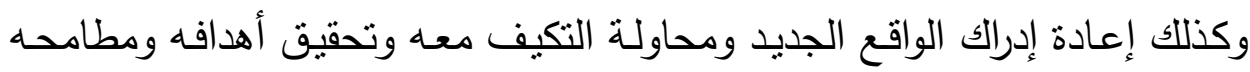
وإشباع حاجاته وفق شـروط البيئة التى يعيش فيها، فالمرونـة التكيفيـة مـاهى إلا إلا

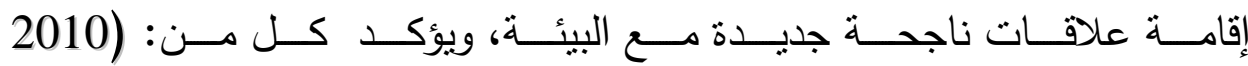
(Bennett,J., ; Ulrichmüller., على مشكلاته، والإلمام بجوانب المشكلة ومعرفـة سُبل مواجهتها، وكيفيـة اختيار الأسلوب الأمثل لحلها، واكتساب المهارات اللازمة للتعامل مع المشكلات. فالمرونة ولاته التكيفية تساعد الفرد فى إزالة ما قد يحدث من توتر ، والمحافظة على حالة الإتزان

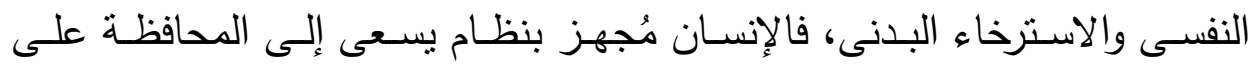
التوازن الداخلى والخارجى. المرونـة التلقائية: وهى " قدرة الفرد على إيجاد طرق جديدة لإشتباع رغباته تبعاً لأى تغيير فى الظروف". فالأفراد المتميزون فى المرونة التلقائية يُمكنهم أن يتخيلوا

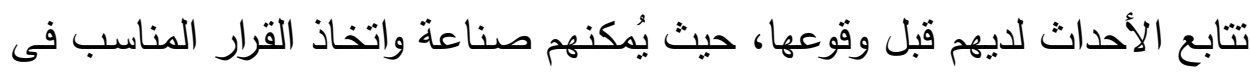


مواجهتها، وإدراك النتائج الإيجابية الصحيحة والسربعة المتوقعة. كمـا أن المرونـة التلقائية تجعل الفرد قادراً على تكوين علاقات إيجابية صحيحة وقوية من خلادل قدرته على التعامل النفسى والاجتماعى والعقلى مع من يحيطون بها، وكذللك تشمل هُله قدرته على التواصل مع ذاته.

من خـال العرض السـابق لمكونات المرونـة العقلية فإن البحث الحالى يتبنى فكرة أن هذا المفهوم قائم على المكونات الثلاثة للمرونة العقلية وهى (المرونة الإدراكية،

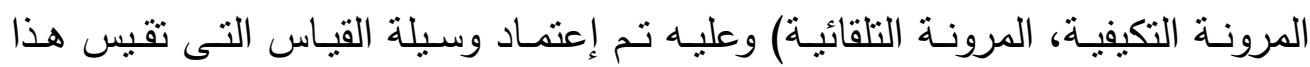
المفهوم.

\section{مقومات المرونة العقلية :}

لقد حدد (2009 ), Ran, R., مقومات المرونة العقلية من خلال دراسته والتى طبقت على طلاب الجامعة، وهى كالتالى: - تتمية الكفاية، وهى تتمية قدرات الفرد العقلية والجسمية والاجتماعية، بحيث تصل وهل

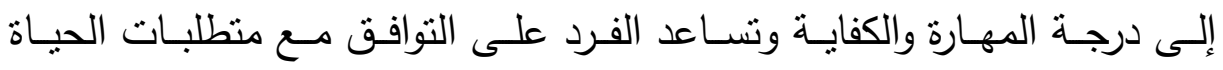
المختلفة.

- القدرة على التعامـل مـع العواطف: هـى نــو قدرة الفـرد على ضـبط انفعالاتهـ

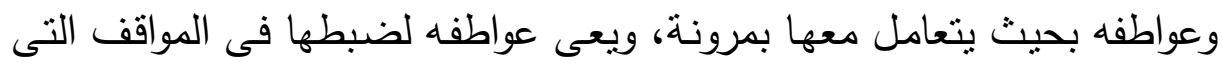
تتطلب ذلك، ويفسح المجال بالتعبير حيثما يتطلب الأمر .

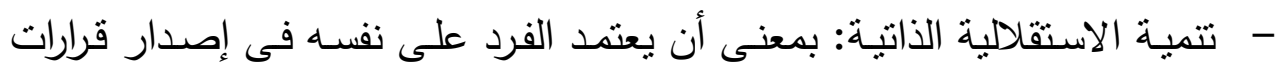

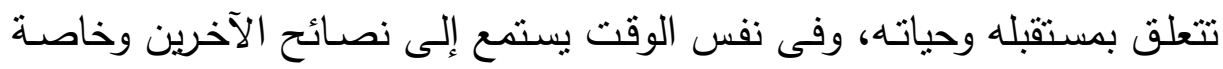

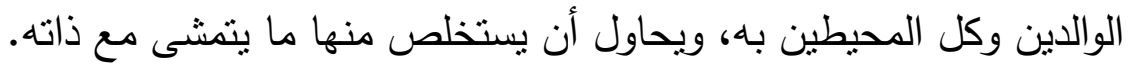

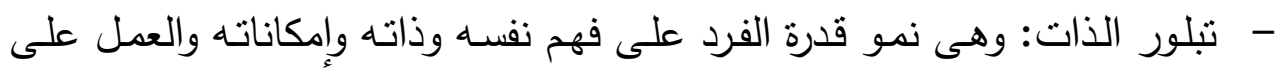
تتميتها، ويضع ذاته ضمن إطار معين بحيث يتلاءم مع الواقع، والشعور الواضح لنخصيته وتأثيرها على كل من يحيط به به.

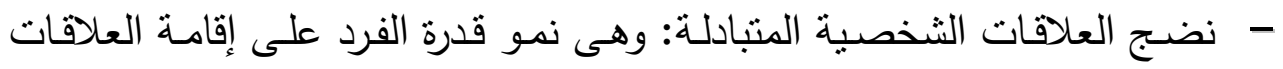

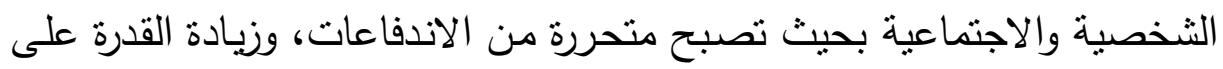
التفاعل والاستجابة بطريقة لها علاقة باستجابة الآخرين وتكون مرنة. 
فلكى يعيش الإنسان حياة مثمرة، يجب عليه أن يتفهم ذاته وبيئته، وأن يتفهم نواحى القوة والضعف عنده، ويكون قادراً على وصف حالة بيئته ومجتمعه وتحليلها بدقة ووعى، وأن بتقبل نقاط قوته وضعفه، والعوامل غير المرغوبـة فى بيئته، ويعتزم Olivia Mobbs ; Katia Lglesias ; تغيير نفسه وبيئنه، وهذا ما أكده (2011) Martial Vander Linden بصفة خاصة كالتالى:

- أن تتوافر لدى الثخص مجموعـة من السمات الثخصية، مس أهمها: الثبات الانفعالى واتساع الأفق والتفكير العلمى التأملى والمسئولية الاجتماعية.

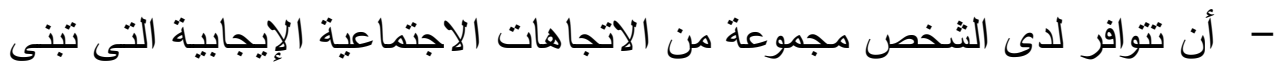

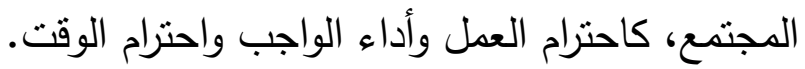

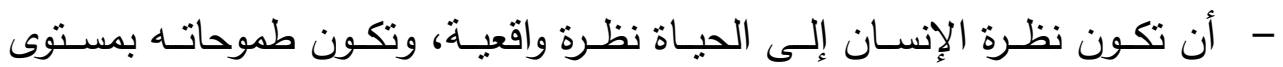
إمكاناته.

فالطالب الذى يتمتع بقدر من المرونة العقلية هو الذى يجد طرقاً جديدة لإثباع

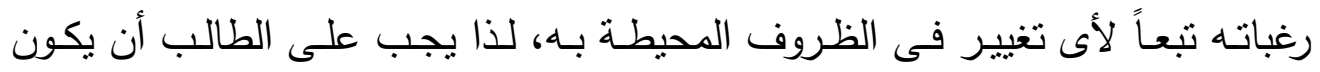
متوافقاً مع ذاته ومتكيف مع نفسه، ويكون راضسى عنها من خلاد النوفيق بين دوافعها

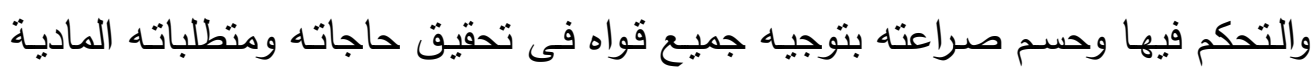

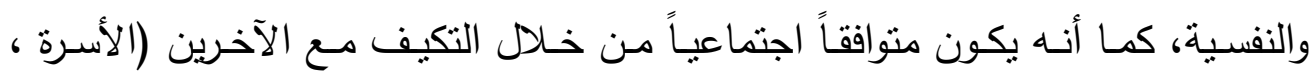
والجامعة، والمجتمع ككل). - ميؤكد البحث الحالي على أن المرونـة بشكل عام والمرونـة العقلية بشكل خاص تجعل الطالب يتتكل مع البيئة التى يعيش فيها وذلك من خلال نقبلها واحترامها

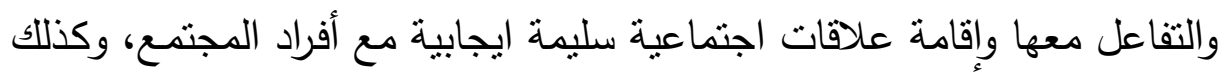

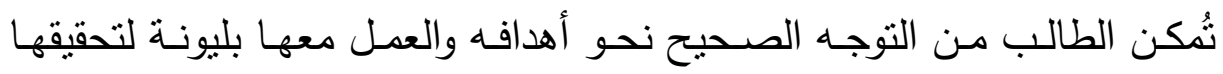
بالثكل السليم. 


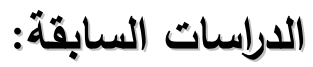 \\ :May Tan (2005) دراسة}

هدفت الدراسـة إلى فحص العلاقة بين المرونـة العقلية (المرونـة الإدراكية)

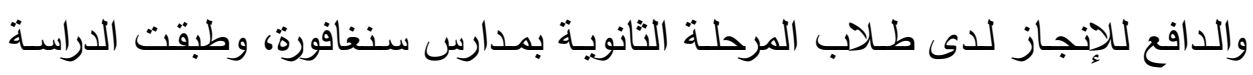
على( . (1) طالب، (0 ) ذكور، (00) إناث، واستخدمت الدراسة مقاييس لقياس العديد من المتغيرات والتى كان من بينها المرونة العقلية والدافع للإنجاز لدى هؤلاء الطلاب، وجاءت نتائج الدراسة كالتالى: - توجد فروق بين الطلاب (الذكور/الإناث) في الدافع للإنجاز وكانت لصـالح

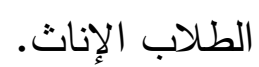
- توجد فروق بين الطلاب (الذكور/الإناث) في المرونة العقلية (المرونة الإدراكية)

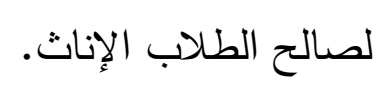
- لم توجد فروق في المرونة العقلية(المرونة الإدراكية) من حيث العمر .

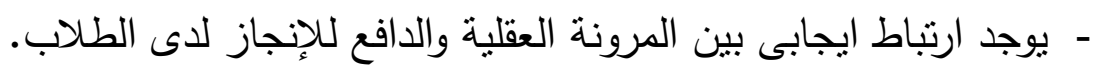

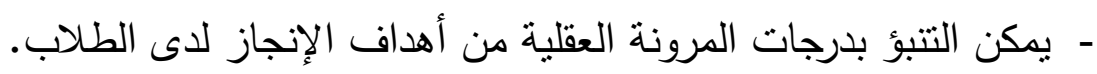

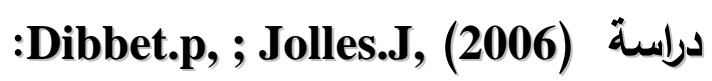

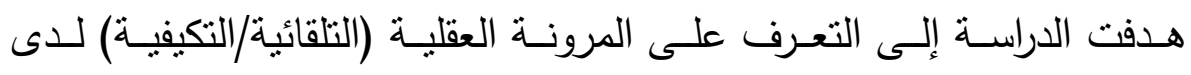

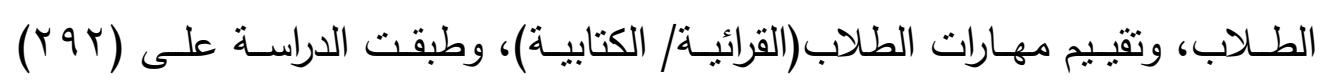

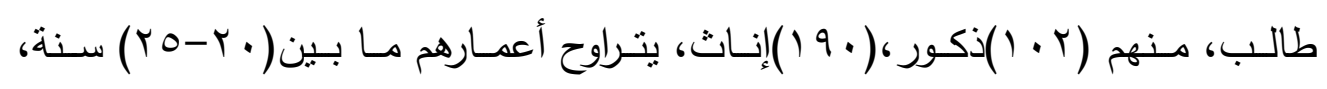

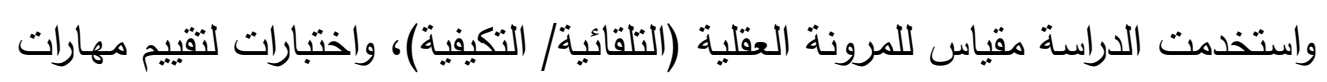
القراءة والكتابة المناسبة للمرحلة العمرية، وجاءت نتائج الدائة الدراسة كالثالى:

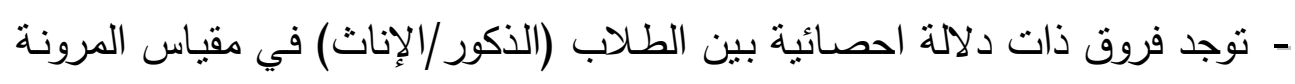

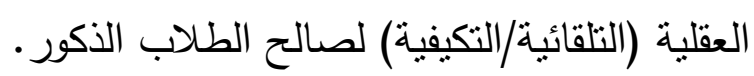


- توجــــــروق ذات دلاهـة إحصــائية بـين الطـلاب فـي مقيـاس المرونــة العقليـة (التلقائية/التكيفية) لصالح الطلاب الأكبر في العمر • - توجد فروق ذات دلالـة إحصـائية بـين الطـلاب (الـكور /الإناث) في اختبـارات مهارات القراءة لصالح الطلاب الإناث. - توجد فروق ذات دلالة إحصائية بين الطلاب في اختبارات مهارات القراءة لصالح

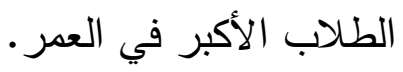
- ل لا توجد فروق ذات دلالة إحصائية بين الطلاب في اختبارات مهارات الكتابة.

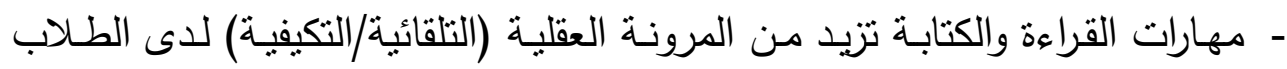
كما تساعدهم على تحسين أدائهر. - تتصح الدراسـة بزيادة الأبحاث في المرونـة العقلية (التلقائية/التكيفية)، لما لها من أثز بالغ على الذاكرة وخاصة عند الطلاب صغار العمر .

\section{:Ran, R.,2009) دراسة}

هدفت الدراسـة إلى بحث العلاقـة ببين المرونـة العقلية(التكيفيـة) وأهداف الإنجاز

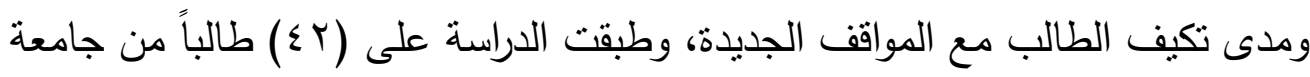

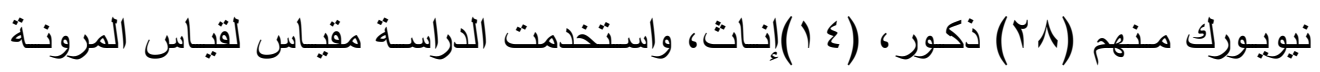
العقلية (التكيفية)، وجاءت نتائج الدراسة كالتالي: - توجد فروق ذات دلالة احصائية بين الطلاب (الذكور / الإناث) في المرونـة العقلية

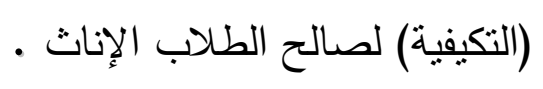

- توجد فروق ذات دلالة احصائية في المرونة العقلية (التكيفية) بين (الذكور /الإناث) ترجع إلى عامل الخبرة وكذللك لبرامج التنمية المستدامة قبل إجراء الدراسة. - يمكن التتبؤ بدرجات المرونة العقلية (التكيفية) من أهداف الإنجاز لدى الطلاب.

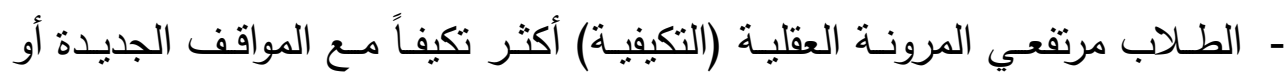
الطارئة. - توجد علاقة ارتباطيه بين المرونة العقلية (التكيفية) وأهداف الإنجاز . 


\section{: Ran, et al(2009) دراسة}

هدفت الدراسـة إلى دراسـة العلاقـة بين المرونـة العقليـة (التلقائيسة) وأهداف

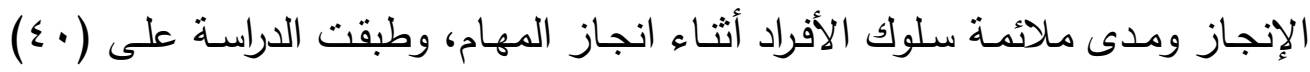

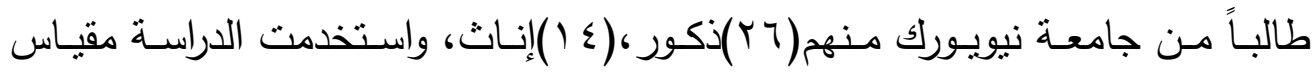
المرونة العقلية (التلقائية) وهو عبارة عن تكوين كلمات وتجميعها في فترة زمنية محددة،

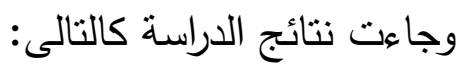
- توجد فروق بين الطلاب في المرونة العقلية (التلقائية) ترجع إلى عامل الخبرة ومن تعرضوا إلى برامج تتمية مستدامه قبل إجراء الدراسة. - وجود فروق ذات دلالة احصائية بين الطلاب (الذكور/الإناث) في المرونة العقلية (التلقائية) لصالح الطلاب الإناث. - ـ يُكن التتبؤ بدرجات المرونة العقلية (التلقائية) من أهداف الإنجاز لاى الطلاب.

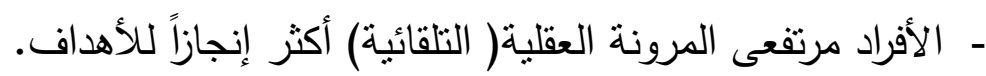
- نوجد علاقة ارتباطية بين المرونة العقلية (التنقائية) وأهداف الإنجاز .

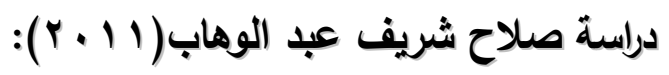

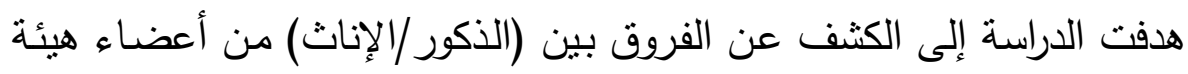

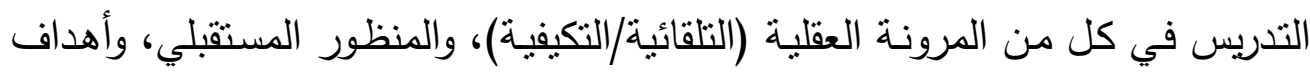

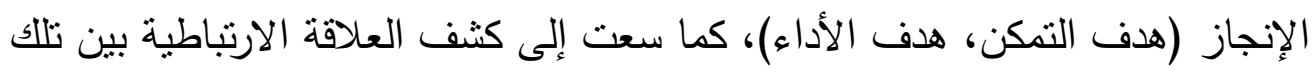

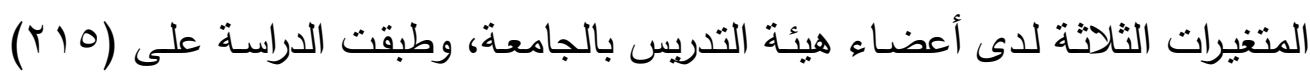

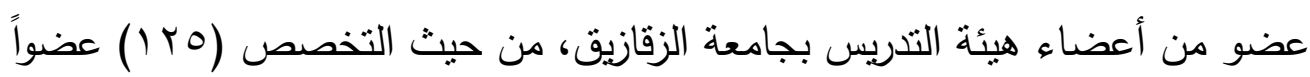

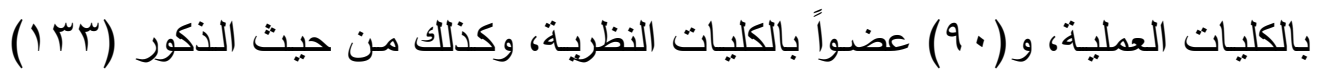

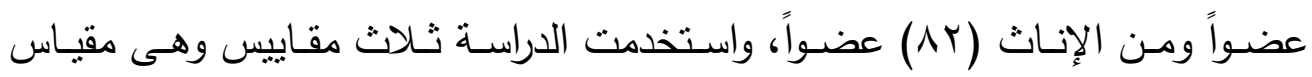

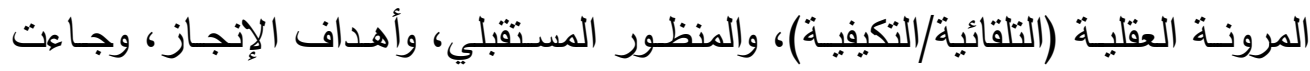

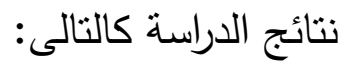


- توجد علاقة ارتباطية بين المرونة العقلية (التلقائية/التكيفية)، (المنظور المستقبلي، أهداف الإنجاز ) لاى أعضاء هيئة التدريس.

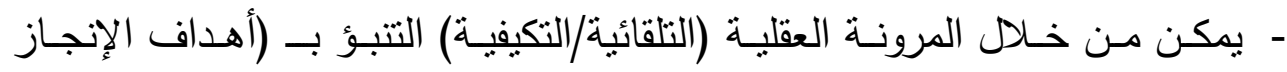
والمنظور المستقبلى) لدى أعضاء هيئة التدريس. - يوجد تأثثر للتفاعل بين التخصص (العلمي/النظري) والنوع (ذكور/اناث)على كل هل من المرونة العقلية (التلقائية/التكيفية) ،أهداف الإنجاز ، والمنظور المستقبلى. - توجد فروق ذات دلالـة احصـائية بين منوسطات درجات أعضـاء هيئة التدريس

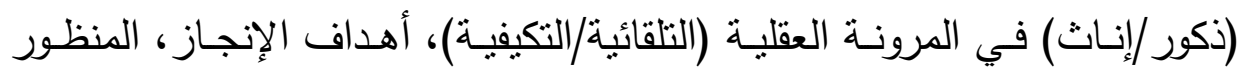
المستقبلى لصالح أعضاء هيئة التدريس الإناث.

\section{:Cynthia, T.,; Steven, E., (2013) دراسة}

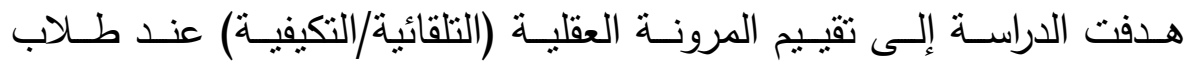
الجامعـة، وفحص العلافـة بـين المرونـة العقليـة (التلقائية/التكيفيـة) والقدرة على حلـ المشكلات والتفكير (الإبـاعي والابتكـاري والتباعدي)، وطبقت الدراسـة على (T7r) طالـب، واسـتخدمت الدراســة مقيـاس لقيـاس الفـروق الفرديـة فـي المرونــة العقليـة (التلقائية/التكيفية)، والقدرة على حل المشكلات باستخدام طرق غير مألوفة، والقدرة على التفكير (الإبـداعي والابتكـاري والتباعدي)، والقدرات المعرفيـة، وجـاءت نتـائج الدراسة كالتالي: - يمكن التتبؤ بالقدرات المعرفية والمهام الإبداعية عند الطلاب من خـلال المرونـة

$$
\text { العقلية (التلقائية/التكيفية) عند طلاب الجامعة. }
$$

- ل لا توجد فروق ذات دلالمة إحصـائية بين منتوسطات درجات الطـلاب في اختبـار

المرونة العقلية (التلقائية/التكيفية).

- يوجــ ارتبـاط إيجـابي بـين المرونـة العقليـة (التلقائية/التكيفيـة) والقدرة على حل

المشكلات. 
- يوجــ ارتبـاط إيجـابي بـين المرونـة العقليـة (التلقائية/التكيفيـة) والتفكير (الإبـداعي والابتكاري والتباعدى) لدى طلاب الجامعة.

- تقترح دراسة المرونة العقلية (التلقائية/التكيفية) في الأبحاث المستقبلية لما لها من تأثثر بالغ على عملية التعليم والتعلم لدى الطلاب.

\section{:Virginie, Etienne., et al(2013) دراسة علية}

هدفت الدراسة إلى فحص أثز المرونة العقلية (الإدراكية) على ذاكرة السائقين،

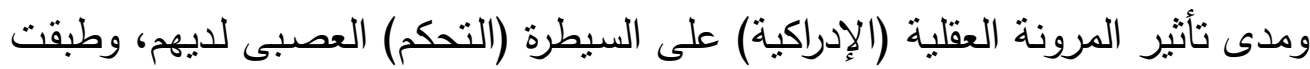

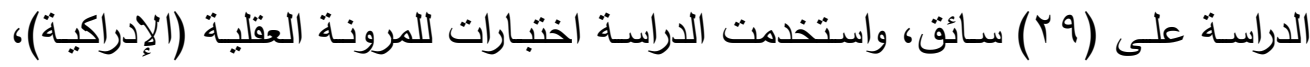

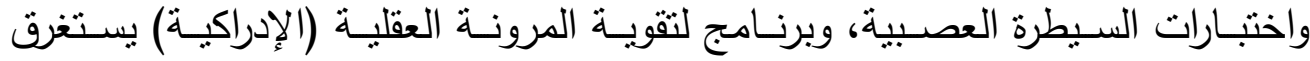
أسبوعين، وجاءت نتائج الدراسة كالتالى: - السائقين الذين ليس لديهم مرونة عقلية(الإدراكية) لا يجيدون التصرف في المواقف المفاجئة. - توجد فروق ذات دلالـة بـين السـائقين في المرونـة العقلية(الإدراكيـة) ترجـع إلى لـ العوامل العصبية. - توجد علاقة بين المرونة العقلية(الإدراكية) والسيطرة العصبية لدى السائقين.

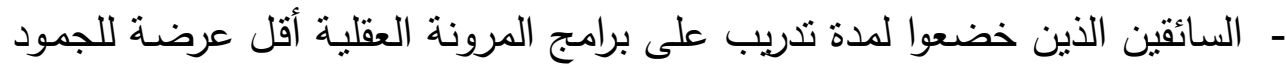
الذهني في المواقف وخاصة المواقف المفاجئة في السواقة.

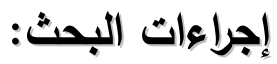

تم اختيـار أفراد العينـة من بين طلبـة وطالبـات الفرقة الأولى والثانيـة والثالثة بكليتى التربية والتربية النوعية بجامعة أسوان بطريقة عشوائية وذلك لتقنين المقياس ،

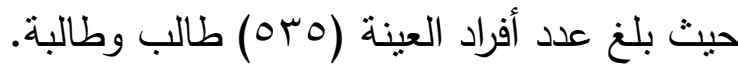
وبعد تطبيق أدوات البحث علي عينة البحث واستبعاد حالات عدم الجدية في البه

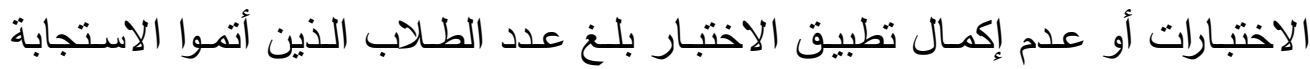

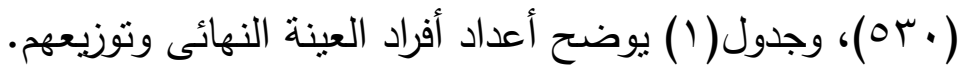


جدول (1)

\begin{tabular}{|c|c|c|c|}
\hline المجموع & التربية النو عية & التربية & \\
\hline $1 T$. & $\varepsilon$. & 9 . & ذكور \\
\hline$\varepsilon \cdots$ & $1 \cdots$ & r.. & إناث \\
\hline or. & $1 \leqslant$. & rq. & المجموع \\
\hline
\end{tabular}

ويتراوح العمر الزمني لأفراد العينة بين • ب - 1 سنة حيث بلغ متوسط العمر

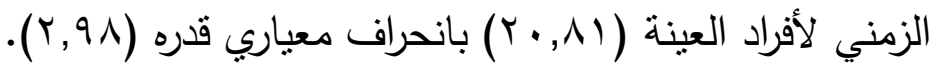

$$
\begin{aligned}
& \text { أدوات البحث : }
\end{aligned}
$$

مقياس المرونة العقلية Mental flexibility Scale (إعداد الباحثة) الهرف من المقياس: يهدف المقياس إلى قياس أبعاد المرونة العقلية لدى طلاب الجامعة، وهذه

$$
\begin{aligned}
& \text { الأبعاد هى: } \\
& \text { - المرونة الإدراكية. } \\
& \text { - المرونة التكيفية. } \\
& \text { - }
\end{aligned}
$$

ويعبر عن هذه الأبعاد بمجموع درجات استجابات الطلاب علي العبارات الإيجابية والسلبية الموجودة بالمقياس والمرتبطة ببعض المواقف التى تعرض عليهخ كمثيرات. تكوين و عاء البنود: Items pool قامت الباحثة الحالية بإعداد هذا المقياس بعد أن تبين لها عدم وجود أداة أجنبية أو عربية لقياس متغير المرونة العقلية تتفق وطبيعة البحث الحالى، وفيما يلي لبي 
عرض للخطوات التى اتبعتها الباحثة الحالية في تصميم هذا المقياس مع بيان أهم معالمه.

استمدت بنود هذا المقياس فى ضوء الإطار النظرى والدراسات السابقة، Ran (R)

Virginie Etienne, et 2013) ؛ (Ran et al, 2009) ؛(,R.,2009

(al, الو هاب، ( 1 • ب) ، (Cynthia,T.,; Steven, E. ,2013).

• تم الاطلاع على بعض المقاييس الأجنبية والعربية التى وضعت لقياس المرونة

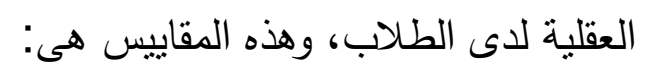

ا ـ مقياس المرونة العقلية Mental flexibility Scale من إعداد May ويهدف هذا المقياس إلى قياس المرونة العقلية لدى طلاب Tan, (2005) المرحلة الثانوية، ويقيس هذا المقياس: المرونة الإدراكية فقط.

r. مقيـاس المرونـة العقليـة Mental flexibility Scale مــن إعـــاد Cynthia,T., ; Steven, E.,(2013) المرونة العقلية لاى طلاب الجامعة ويقيس هذا المقياس بعدين هما: * * المرونة التلقائية. المرونة التكيفية.

r. مقياس المرونة العقلية Mental flexibility Scale من إعداد صـلاح شريف عبد الوهاب، | | ـ ب ويهدف إلى الكثف عن الفروق بين الذكور

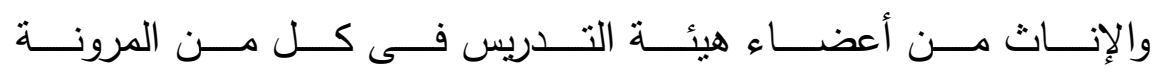

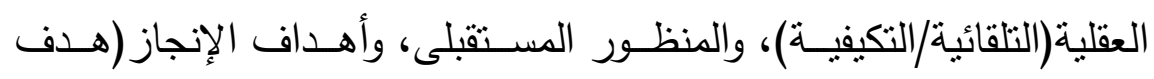
التمكن، هدف الأداء)، ويقيس هذا المقياس بعدين هما: * المرونة التكيفية. • المرونة التلقائية.

وعلى الرغم من اطلاع الباحثة الحالية على المقاييس السـابقة لقياس المرونـة العقلية فقد تم إعداد مقياس المرونة العقلية في البحث الحالي للأسباب الآتية: 
بعض المقاييس السـابق ذكرهـا تسـتخدم مـع عينـة مختلفـة عـن عينـة البحـث

$$
\text { الحالي. }
$$

بعض المقاييس نم تطبيقها في بيئة مختلفة عن بيئة البحث الحالي. بعض المقاييس لا تحتوى على عدد كبير من العبارات تغطي جميع الأبعاد. المقاييس السابقة تكتفى بقياس بُعد أو بُعدين لقياس المرونة العقلية.

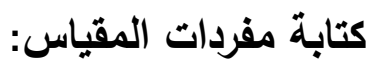
اعتمـاداً على الخطوتين السـابقتين تم صياغة مفردات المقياس بإتباع طريقة Likert 1- أن تعبر كل عبارة عن فكرة واحدة فقط. r- أن تكون بسيطة وسهلة حتى يمكن فهمها. r- أن تكون مرتبطة بالحياة والواقع الذي يعيش فيه الطالب.

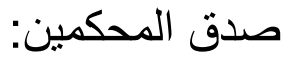

تم عرض المقياس على مجموعـة من المتخصصين من أسـاتذة علم النفس،

$$
\text { وطلب من كل منهم إبداء الرأي من حيث: }
$$

ا ـ ـ مدى وضوح العبارات للمهام التى تتنمي إليها. r. مدى مناسبة العبارات للمستوى العمرى لأفراد العينة. r. عبارات يرون تعديلها أو إضافتها أو حذفها.

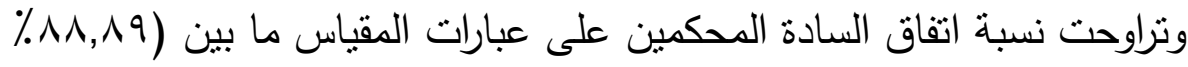

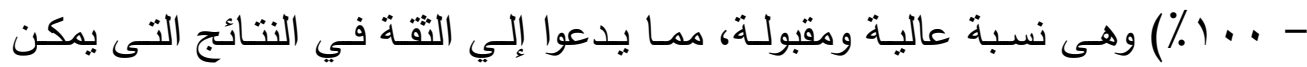
التوصل إليها من خلال تطبيق المقياس على أفراد العينة، وتضمنت ملاحظات السـادة

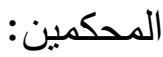

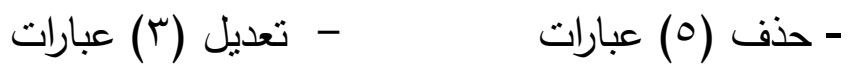

وأخذت الباحثة بالمقترحات التى قدمها السادة المحكمين وعدلت المقياس بناءاً على ذلك. كهُ الكفاءة السيكومترية للمقياس:

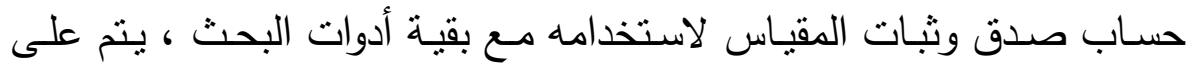
النحو التالي: 
أـ- صدق المقياس فى البحث الحالى:

تم حساب صدق المقياس باستخدام: صدق التحليل العاملي:

تم اسـتخدم التحليـل العـاملى الاستكثـافى لتقدير الصـدق العـاملى للمقبـاس بطريقـة المكونات الأساسية Hotling لـ principal Components وتم التدوبر المتعامد بطريقة Varimax، كما نم اختيار التشبعات الدالة على العوامل المستخلصة وفقاً لما يلى : - العامل الجوهري هو ما كان له جذر كامن أكبر من الواحد الصحيح. - - محك التشبع الجوهرى للعبارة >

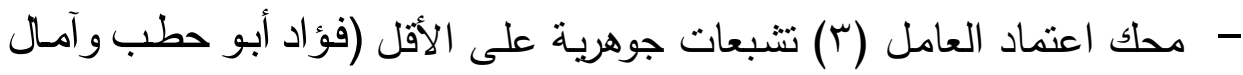

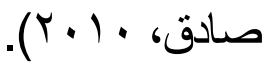
وبناء على انتقاء العبارات وفقاً لهذه المحكات الثناثة السـابقة فقد تم انتقاء العبارات ذات التشبعات التى تزيد على (r, •) وتصنيفها على العامل الذى كان تشبعها عليه أكبر، فكانت نتائج التحليل على النحو التالي:

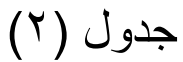

تشبعات مفردات مقياس المرونة العقلية بالعو امل بعد التذوير وجذور ها الكامنة

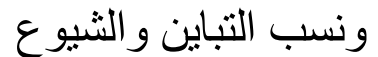

\begin{tabular}{|c|c|c|c|c|c|c|c|c|c|}
\hline \multirow{2}{*}{ 手葛. } & \multicolumn{3}{|c|}{ العو امــــــلـ } & \multirow{2}{*}{. } & \multirow{2}{*}{ 手高章 } & \multicolumn{3}{|c|}{ العو امــــــلـ } & \multirow{2}{*}{ ר) } \\
\hline & 司 & 挙 & $\stackrel{\bar{\pi}}{\bar{J}}$ & & & 牙 & $\overline{7}$ & 亏) & \\
\hline י, גז & & & $\because, 9 \ldots$ & $r 9$ & $\cdot, 119$ & & & $\cdot, r \leqslant 0$ & 1 \\
\hline , $9 \mathrm{Tr}$ & & $\cdot, 9 \leqslant 9$ & & $\xi$. & $\cdot, \cdot r$ &., $10 \mathrm{~V}$ & & & $r$ \\
\hline .91. & 9,97 & & & $\sum 1$ & $\cdot, I V Y$ & & & $\cdot, \leqslant 00$ & $r$ \\
\hline$\because .09$ & & & 0,199 & $\varepsilon Y$ & 0,17 & & & $\cdot, r \cdot \varepsilon$ & $\varepsilon$ \\
\hline$\cdot, 1 \wedge \wedge$ & & $\cdot, \varepsilon \cdot Y$ & & $\varepsilon r$ & $\cdot, 194$ & & $\cdot, \varepsilon \cdot 7$ & & 0 \\
\hline$\cdot, 1 \leq \varepsilon$ & $\cdot r, \mu$ & & & $\varepsilon \varepsilon$ & $\cdot, 1 \leqslant r$ & , ro. & & & 7 \\
\hline$\cdot r \circ \Lambda$ & & & $\because, 0 \vee \wedge$ & $\varepsilon 0$ & $\cdot, \pi 4$ & & & $\cdot, 0 \wedge V$ & $V$ \\
\hline י ג ג & & & $\cdot, 190$ & $\varepsilon 7$ & $\cdot, \wedge \cdot 1$ & & & $\cdot, \wedge \wedge 9$ & $\wedge$ \\
\hline$\cdot, 9 \pi \mathrm{V}$ & &., 97. & & $\varepsilon V$ & $\cdot, 91 Y$ & & $\cdot, 9 \leqslant 1$ & & 9 \\
\hline
\end{tabular}




\begin{tabular}{|c|c|c|c|c|c|c|c|c|c|}
\hline \multirow{2}{*}{ 手雪 } & \multicolumn{3}{|c|}{ العو امـــــلـلـ } & \multirow{2}{*}{$\frac{\overline{7}}{9}$} & \multirow{2}{*}{ 当䓪 } & \multicolumn{3}{|c|}{ العو امـــــلـل } & \multirow{2}{*}{$\frac{7}{3}$} \\
\hline & 雪 & 牙 & $\stackrel{\bar{x}}{5}$ & & & 司 & $\overline{7}$ & 亏 & \\
\hline$\cdot, 90 r$ & $\cdot 970$ & & & $\varepsilon \Lambda$ & $\cdot 91 \pi$ & $\cdot 904$ & & & 1. \\
\hline$\cdot, \wedge r u$ & & & $\cdot \wedge १ \vee$ & $\varepsilon 9$ & $\because \cdot 7$ & $\cdot, 1 T_{4}$ & & & 11 \\
\hline$\cdot 911$ & & $\cdot, 90$. & & 0. & $\cdot, 194$ & & $\cdot, \varepsilon \cdot 7$ & & 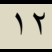 \\
\hline$\cdot, 90 Y$ & $\cdot, 9 V Y$ & & & 01 & $\cdot, 1 \leq r$ & $\cdot r \leqslant 0$ & & & 11 \\
\hline$\cdot, .09$ & & $\cdot, 199$ & & OY & $\cdot, \pi 41$ & & & $\because, 0 \wedge \mathrm{V}$ & $1 \varepsilon$ \\
\hline$\cdot, \wedge \wedge$ & & & $\cdot, 1 \leq \varepsilon_{-}$ & or & $\cdot, \wedge \cdot 1$ & & & $\cdot, \wedge \wedge 9$ & 10 \\
\hline$\cdot, 1 \leq \leqslant$ & $\cdot, M \wedge$ & & & $0 \leqslant$ & $\cdot, q 1 r$ & & $\cdot, 9 \leqslant \wedge$ & & 17 \\
\hline$\cdot, r 01$ & & &., $0 \vee \wedge$ & 00 & $\cdot 91 \pi$ & $\because, 904$ & & & IV \\
\hline$\cdot, \wedge r q$ & & & $\cdot, \wedge 9 \wedge$ & 07 & $\cdot, r 01$ & & & $\cdot, 0 \vee \wedge$ & 11 \\
\hline$\cdot, 9 \ldots$ & & $\cdot, 900$ & & $O V$ & , גזч & & & $\cdot 91$. & 19 \\
\hline$\cdot, 917$ & $\because, 901$ & & & 01 & $\cdot, 9 M \mathrm{~V}$ & & $\therefore, 901$ & & $r$. \\
\hline$\cdot, \wedge r_{4}$ & & & $\cdot 911$ & 09 & $\cdot, 91 \mathrm{~V}$ & $\cdot, 974$ & & & YI \\
\hline$\cdot, 911$ & & $\cdot, 9 \leq 9$ & & 7. & $\cdot, .09$ & $\cdot, 199$ & & & rr \\
\hline$\cdot, 9 \varepsilon \cdot$ & $\cdot 970$ & & & 71 & $\cdot, 1 \wedge \wedge$ & & $\cdot, \varepsilon \cdot Y$ & & $r r$ \\
\hline$\cdot .09$ & 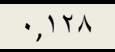 & & & $7 r$ & $\cdot, 1 \leq \varepsilon$ & $\cdot, r / \Lambda$ & & & $r \varepsilon$ \\
\hline$\cdot, 1 \wedge \wedge$ & & $\cdot, \varepsilon \cdot r$ & & 74 & $\cdot$, r०ג & & & $\cdot, 0 \vee \wedge$ & ro \\
\hline$\cdot, 1 \leq \varepsilon$ & ת זrז, & & & $7 \varepsilon$ & $\cdot, \wedge r 4$ & & & $\cdot 9 \ldots$ & $r 7$ \\
\hline$\cdot, r 01$ & & & $\because, O V V$ & 70 & $\cdot 9 \mu \mathrm{V}$ & & $\because 90$. & & $r V$ \\
\hline •, Кז & & & $\bullet, \wedge q$. & 77 & $\cdot, 91 r$ & & $\cdot, 9 \vee$. & & $r \wedge$ \\
\hline$\cdot, 91 \leqslant$ & & $\cdot, 90 \leq$ & & $7 V$ & $\cdot, \wedge r 4$ & & & $\cdot, \wedge 91$ & rq \\
\hline$\cdot, 90 \mathrm{r}$ & $\cdot 9 \times 1$ & & & 71 & $\cdot, 914$ & & $\cdot 904$ & & $r$. \\
\hline •, Аाт & $\cdot, 911$ & & & 79 & $\cdot, 90 \mathrm{r}$ & & $\because, 9 \vee \cdot$ & & $\Gamma$ \\
\hline$\cdot, q 1 r$ & & $\cdot, 90$. & & $v$. & $\because, .09$ & & $\because, 199$ & & rT \\
\hline$\cdot, 9 \ldots$ & $\cdot, 9 V Y$ & & & VI & $\cdot, \wedge \wedge$ & & $\cdot, \varepsilon \cdot Y$ & & rT \\
\hline$\cdot .09$ & & & $\cdot, 199$ & $V Y$ & $\cdot, 1 \leq \varepsilon$ & $\cdot, r \wedge \wedge$ & & & $\Gamma \varepsilon$ \\
\hline$\because, 1 \wedge \wedge$ & & $\cdot, \varepsilon \cdot r$ & & $V r$ & $\cdot, r \circ \Lambda$ & & & $\because, 0 \vee \wedge$ & ro \\
\hline$\cdot, 1 \leq \varepsilon$ & :, $4 \pi q$ & & & $V \varepsilon$ & $\cdot, \wedge r ч$ & & & $\cdot, \wedge 99$ & $r 7$ \\
\hline \multirow[t]{4}{*}{$\cdot r 01$} & $\because, 0 \vee \wedge$ & & & Vo & $\therefore, 9 \ldots$ & & $\cdot, 909$ & & rV \\
\hline & & & & & $\cdot, 91 r$ & $\cdot, 979$ & & & $\mu \wedge$ \\
\hline & $1 r, \varepsilon r q$ & 14,017 & $1 \varepsilon, 101$ & \multicolumn{6}{|c|}{ الجذور الكامنة } \\
\hline & $1 v, 919$ & $|\Lambda, \cdot r|$ & $19,7 \vee 1$ & \multicolumn{6}{|c|}{ نسبة التباين الكلى } \\
\hline \multicolumn{4}{|c|}{$\% 00,71 \wedge$} & \multicolumn{6}{|c|}{ نسبة التباين المجمع } \\
\hline
\end{tabular}


يتضـح من الجدول السـابق أن عدد العبارات المستخلصـة (70) عبارة موزعـة

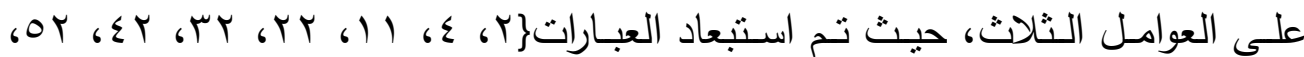

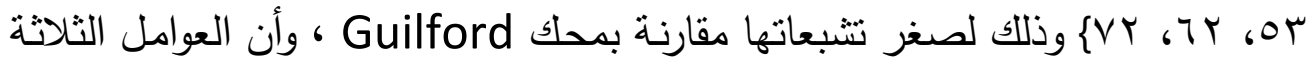

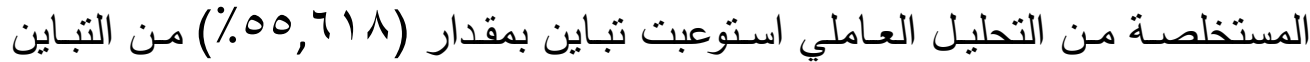
الكلى لمتغيرات المصفوفة. وشكل(r) التالي يوضـح أن قيم الجذور الكامنة تتـاقص تدريجياً ابتداءَ مـن العامل الأول حيث لـه أكبر جذر كامن وحتى العامل الثالث وله أقل جذر كامن لأن التحليل العاملى يستخرج الحد الأقصى المدكن لتباين كل عامل فى كل مرة.

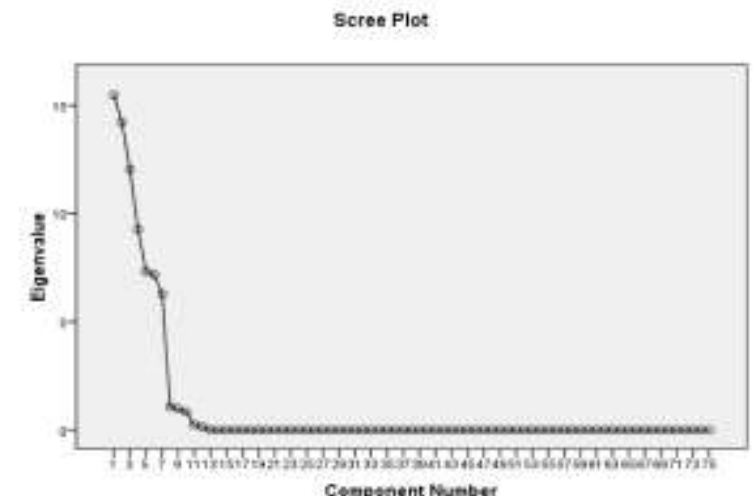

Compenent Number

شكل (Y) يوضح العلاقة بين العو امل و الجذور الكامنة

ويبين جدول (ع)الجذور الكامنة والنسب المئوية لتباين العوامل المستخلصة من

التحليل العاملى لعبارات المقياس بعد التدوير المتعامد.

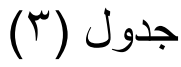

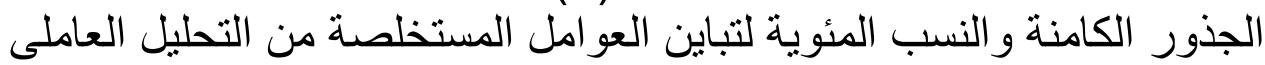
لمفردات مقياس المرونة العقلية بعد التدوير المتعامد المدان

\begin{tabular}{|c|c|c|c|}
\hline النسب المئوية لتباين العامل & الجذور الكامنة & ترتيب العامل & م \\
\hline$\% 19,7 \vee \wedge$ & $1 \varepsilon, 101$ & الأول & 1 \\
\hline$\% \backslash \wedge, \cdot Y \backslash$ & 11,017 & 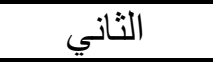 & $r$ \\
\hline$\% 1 \vee, 919$ & $1 r, \varepsilon r q$ & الثالث & $r$ \\
\hline
\end{tabular}


من جدول (ץ) يمكن استخلاص العو امل التالية: ا ـ العامل الأول:

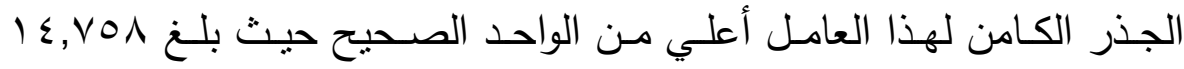

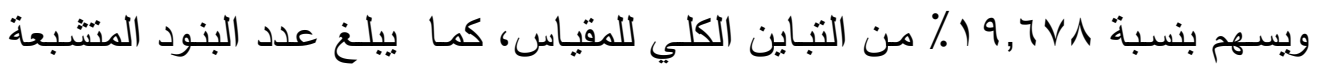

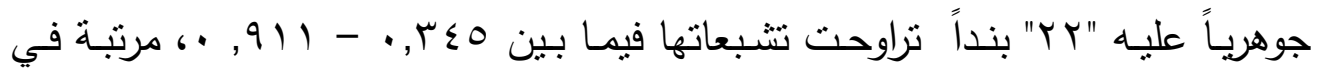
جدول (ع) طبقاً لقيم تشبعاتها بالعامل.

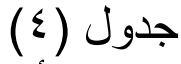

تشبعات المفردات على العامل الأول لمقياس المرونة العقلية

\begin{tabular}{|c|c|c|}
\hline التشبعات & 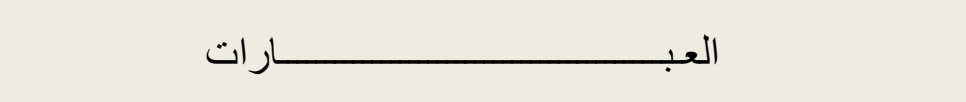 & العبارة \\
\hline$\cdot, 911$ & أصدر أحكاماً على أفكارى ومفاهيمى سواء كانت جيدة أو سيئة. & 09 \\
\hline$\cdot, 91 \cdot$ & لدى حب استطلاع لمعرفة و إدر الك ما حولى. & 19 \\
\hline$\cdot, 9 \ldots$ & أر اعى اختلاف المفاهيم باختلاف السياقات المستخدمة فيها. & ry \\
\hline$\cdot, 9 \cdots$ & اسامح و اغفر لنفسى وللآخرين. & ra \\
\hline$\cdot, 199$ & اتضنايق من اختلاف الر أى حول قضية ما. & Th \\
\hline$\cdot, \wedge 9 \wedge$ & أقوم بتحليل المشكلة إلى عناصر بسيطة. & rq \\
\hline$\cdot, \wedge 9 \wedge$ & تحدياتها أن متعة الحياة و إثارتها تكمن فى قدرة الفرد على مو اجهة & 07 \\
\hline$\cdot, \wedge 9 \vee$ & لاى قدر على المثابرة حتى انتهى من حل أى مشكلة تو اجهنى. & $\leqslant 9$ \\
\hline$\because, 190$ & أرحب كثيراً بالمناقشنات والحو ار مع الآخرين. & $\sum 7$ \\
\hline$\cdot, \wedge 9$ & أعتقد أن سوء الحظ يعود إلى سوء التخطيط. & 77 \\
\hline$\cdot, \wedge \wedge 9$ & اركز فقط فيما أفعله و لا شئ أخر. & 10 \\
\hline$\cdot, \wedge \wedge 9$ & يُضِايقنى جداً اللوم و العتاب حتى لوكنت استحقه. & $\Lambda$ \\
\hline$\cdot, 0 \wedge \mathrm{V}$ & لا بد أن أرد الإساءة مهما كانت العو اقب. & $\mathrm{V}$ \\
\hline$\cdot, 0 \wedge \mathrm{V}$ & أ عتقا أن الشخص بستطيع بناء مستقبله بنفسه. & $1 \varepsilon$ \\
\hline$\because, 0 \vee \wedge$ & يُمكننى أن أتغاضى بسهولة عن أخطاء الآخرين. & ro \\
\hline$\cdot, 0 \vee \wedge$ & أعتقد أن الفشل يعود إلى أسباب تكمن فى الشخص نفسه. & Yo \\
\hline$\cdot, 0 \vee \wedge$ & الاعتر اف بالخطأ أمر عسير بالنسبه لى. & 00 \\
\hline$\cdot, 0 \vee \wedge$ & استطيع توجيه النقد لنفسى دون هدم. & $\leqslant 0$ \\
\hline., $0 \vee \wedge$ & أقوم بتقييم إنجاز اتى الأسبو عية. & 11 \\
\hline., $0 V V$ & عندما أضع خططى المستقبلية، غالباً ما أكون متأكداً من قدرتى على & 70 \\
\hline
\end{tabular}




\begin{tabular}{|c|c|c|}
\hline التشبعات & 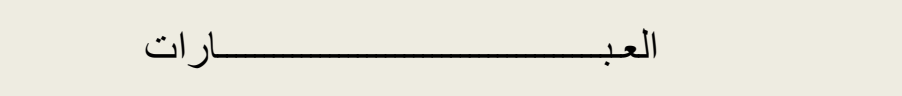 & العبارة \\
\hline$\because, \leqslant 00$ & أحترم الآر اء المتباينة و المختلفة عن ر أيى عند مو اجهة المو اقف. & r \\
\hline$\cdot r \leqslant 0$ & أثثق فى قدر اتى على التعامل مع المشاكل الصعبة. & $T$ \\
\hline
\end{tabular}

وبلاحظ على محتوى البنود المتشبعة على هذا العامل أنها نتركز حول" قدرة

الفرد على معرفة الاستجابات المناسبة للموقف والتفكير بمرونـة لتطوبر الاسـتجابات البديلة وتعديل واستبدال الاستجابات الخاطئة بالصـيحة واحترام الرأى والرأى الأخر والسـيطرة على الأشـياء المعقدة" ، لـذلك يمكن تسـمية هـذا العامـل بـ "المرونــة

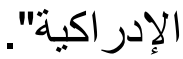

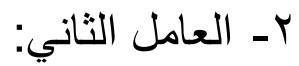

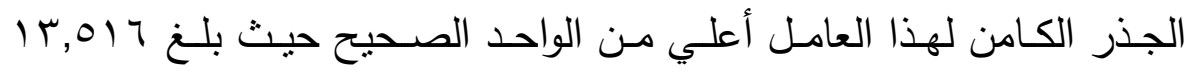

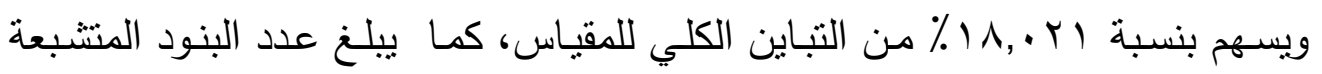

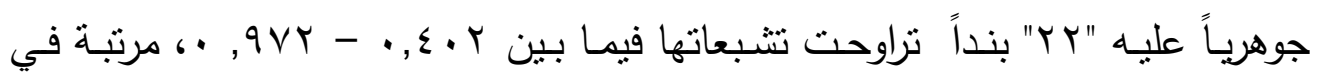
جدول (0) طبقاً لقيم تشبعاتها بالعامل.

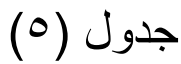

تشبعاث المفردات علي العامل الثانى لمقياس المرونة العقلية

\begin{tabular}{|c|c|c|}
\hline التشبعات & 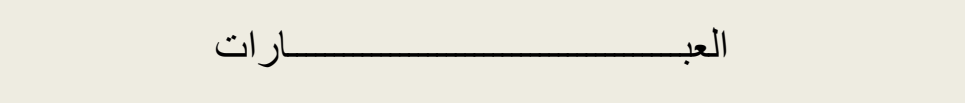 & 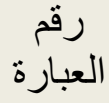 \\
\hline$\therefore, 9 \vee r$ & بسبب كثرة المشكلات لا أستطيع التخطيط للمستقبل. & ו \\
\hline$\cdot, 9 \vee \cdot$ & أقبل التغيير و التعديل حسب كل موقف. & r人 \\
\hline., 97. & ابحث عن عدة طرق للتعامل مع المشكلات. & $\varepsilon V$ \\
\hline., 909 & مهما كانت العقبات فإننى أستطيع تحقيق أهدافى. & rV \\
\hline., 901 & أخطط لمستقبل أفضل حتى فى الأوقات القاسية. & Y. \\
\hline$\cdot, 900$ & مختلفة مو اجهة صعوبة فى تحقيق الأهداف، احاول انجاز ها بعدة طرق & ov \\
\hline $.90 \leqslant$ & أسنطيع التغلب على المصائب مهما كانت. & $7 V$ \\
\hline$\cdot, 901$ & أستطيع التكيف مع التغيير ات المستحدثة. & r. \\
\hline .90 & أشعر بعدم السيطرة على الأشباء المهمة فى حياتى. & $V \cdot$ \\
\hline .90 & تُداهمنى الضغوط فى الجامعة نظر اً لجمودى الذهنى فى التعامل. & tr \\
\hline
\end{tabular}




\begin{tabular}{|c|c|c|}
\hline التشبعات & 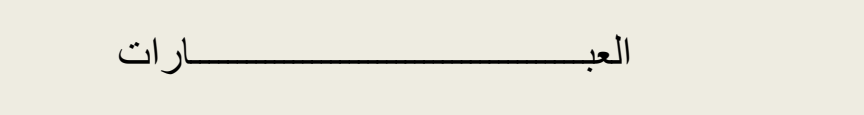 & العبارة \\
\hline$\because, 90$. & أُغير قيمى ومبادئى إذا دعت الظروف لذلك. & 0. \\
\hline$\cdot, 9 \leq 9$ & أستعبد توازنى بسر عة بعد الأوقات الصعبة. & $\varepsilon$. \\
\hline$\cdot 9 \leq 9$ & أتجنب المو اقف التى تجعلنى جامد ذهنياً. & 7. \\
\hline$\cdot, 9 \leq 1$ & أتجنب القيام بالأشياء عند الشعور بالخطر. & 9 \\
\hline$\cdot 9 \leq 1$ & على الإنسان أن يُخير أسالييه حتى يصل إلى الهرف. & 17 \\
\hline$\cdot, \varepsilon \cdot 7$ & لا أتغلب على المشكلات عند تر اكمها. & 0 \\
\hline$\cdot, \varepsilon \cdot 7$ & أثعر بالخوف من مو اجهة المشكلات حتى قبل أن تحدث. & IT \\
\hline$\cdot, \varepsilon \cdot r$ & يُمكنى تطويع الفكرة لكى تتناسب مع الموقف الذى يو اجهن. & r \\
\hline$\cdot, \varepsilon \cdot r$ & أستطيع التكيف مع المشكلات الحياتية. & $\varepsilon$ \\
\hline$\cdot, \varepsilon \cdot r$ & أستعين بالآخرين فى حل المشاكل التى تو اجهن. & 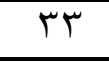 \\
\hline$\cdot, \varepsilon \cdot r$ & أشعر بالر هبة و الخوف عند التعرض لمو اقف جديدة. & Tr \\
\hline$\cdot, \varepsilon \cdot r$ & أستطيع استعادة توازنى بعد حدوث اشياء مُفرحة فى حياتى. & $V T$ \\
\hline
\end{tabular}

وبلاحظ على محتوى البنود المنتبعة على هذا العامل أنها تتركز حول " قدرة

الفرد الإيجابية على التكيف مع ضنوط الحياة مدا بُمكنه من أداء وظائفه بشكل جيد والتغييـر والتعـديل لمسـايرة الأمسور "، لـذلك يمكن تسـمية هـذا العامـل بـــ "المرونــة التكيفبنة" و

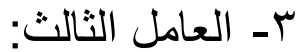

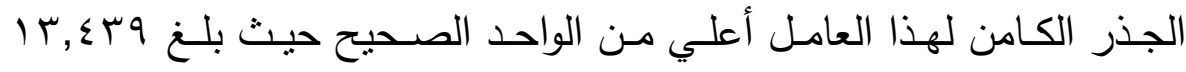

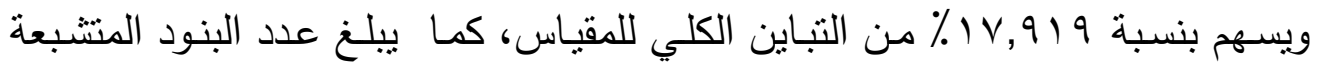

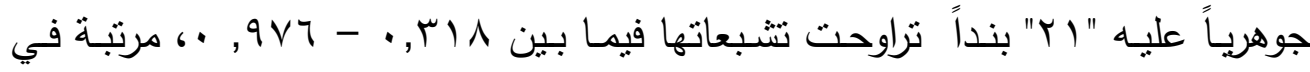
جدول (7) طبقاً لقيم تشبعاتها بالعامل.

(7) جدول) (1)

تشبعات المفردات على العامل الثالث لمقياس المرونة العقلية

\begin{tabular}{|c|c|c|}
\hline التشبعات & 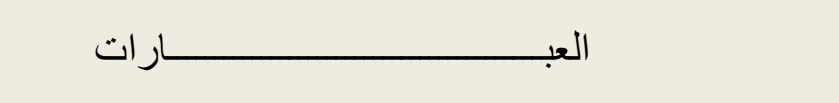 & العبارة \\
\hline$\because, 9 \vee r$ & أحاول إعطاء دلائل كثيرة لآرائى ومعتقداتى. & $\sqrt{11}$ \\
\hline$\cdot, 9 \vee Y$ & ا اهتمامى بنفسى لا يتر ك لى فرصة للتفكير فى أى شئ آخر. & 01 \\
\hline
\end{tabular}




\begin{tabular}{|c|c|c|}
\hline التشبعات & 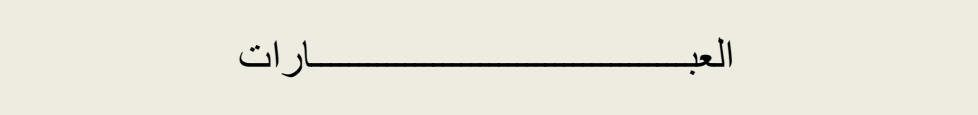 & 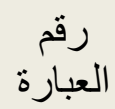 \\
\hline$\cdot, 9 \times 1$ & أتعامل مع الآخرين بأساليب مختلفه منها الأبتسامة و الضحك. & $7 \wedge$ \\
\hline$\cdot 9 \vee$ & أبحث عن التجارب الحياتية لأنها تُكسبنى تتو عاً فى الأفكار. & rA \\
\hline$\cdot, 9 \vee \cdot$ & الحياة الثابتة هى الحياة الممتعة بالنسبة لى. & M \\
\hline., 979 & لا أقيد أفكارى تحت إطار محدد أثناء مو اجهتى للمشكلة. & r人 \\
\hline$\cdot 970$ & الجمر ارى الفكى فتوى تنوع الأفكار حول المو اقف التى تواجهنى تخرجنى من & $\leqslant \curlywedge$ \\
\hline$\cdot, 970$ & وجا أمانع فى تكر ار محاو لاتى لحل مشكلة ما مهما كلفنى ذلك من وقت & 71 \\
\hline$\cdot, 97 r$ & حلها. أستخدم الأفكار غير التقليدية فى مواجهة مشكلة ما طالما يُسهم فى & Y) \\
\hline., 97. & أحاول انجاز المهمات بأكثر من طريقة مختلفة. & $\varepsilon 1$ \\
\hline., 901 & أضع جميع الإحتمالات فى حل المشكلة و أختار انسبها. & 01 \\
\hline$\cdot, 90 \mathrm{r}$ & غريبة. لأقل من إنتاج الأفكار حول موضوع ما، حتى ولو كانت أفكار & iv \\
\hline$\cdot, 90 \mathrm{r}$ & زملائى. إلى إنتاج أكبر قدر من الأفكار حول موضوع ما عند مشاركة & $1 \cdot$ \\
\hline$\cdot$ & أحاول الإنتباه إلى المجمو عات المتنوعة من الرسائل و الأفكار & 7 \\
\hline .,$\Gamma \leqslant 0$ & أنظر إلى الأمور بمنظور ثابت وو احد . & 14 \\
\hline • & أبتعد عن الأشخاص الذين لا يرون غير آر ائهم فى حل المشكلة. & $V \varepsilon$ \\
\hline 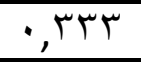 & أبحث عن حلول مختلفة عند مو اجهة المشكلات. & $7 \varepsilon$ \\
\hline 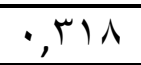 & أتطرق بذهنى لأفكار غريبة ومستحيله لعلاج المشكلة. & $r \leqslant$ \\
\hline •, M & أستخدم فى حديثى كلمات مرنة وليست قاطعة. & rs \\
\hline ill & من السهل التفكير فى طرق جديدة و غير تقليدية لتعديل السلوك. & of \\
\hline$\cdot, \mu$ & أتخطى العقبات بكل سهولة من خلال أفكارى المتنو عة. & $\varepsilon \xi$ \\
\hline
\end{tabular}

ويلاحظ على محتوى البنود المتتبعة على هذا العامل أنها تتركز حول " قدرة الفرد

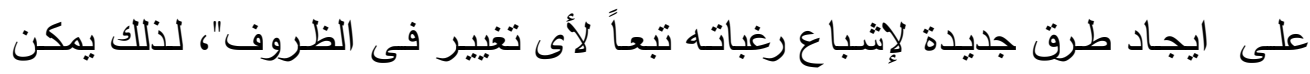
تسمية هذا العامل بـ-"المرونة التلقائية".

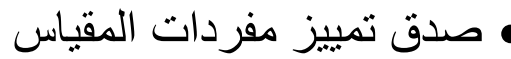


"يشير معامل تمييز المفردات Item discrimination index إلى قدرة المفردة على التمييز بـين المجموعـات المتباينـة فيى الأداء، أى بـين المجموعـات العليـا والدنيا، أو بين المتفوقين الذين أثقنوا تعلم الموضوع ولديهم الكثير من المعرفة عنهـ والمتأخرين الذين فثلوا فى تعلمه ولا يعرفون إلا القليل من المعرفة عنه، كما أنه كلما كانت قيمة معامل التمييز مرتفعة كان ذلك أفضل لأن ذلك يؤدى لزيادة قدرة

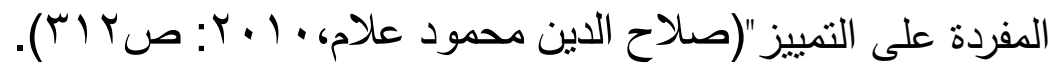
تم حساب صدق تمييز مفردات مقياس المرونة العقلية من خلال أخذ الدرجة الكلية لكل بعد من أبعاد مقياس المرونة العقلية (تلاثتة أبعاد) محكاً للحكم على صدق الته

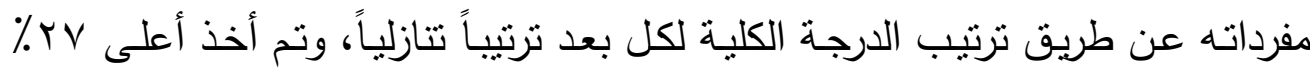

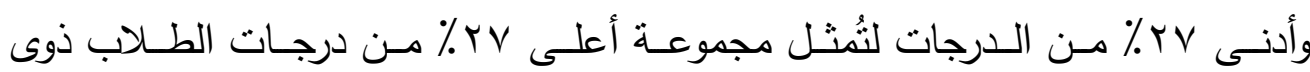

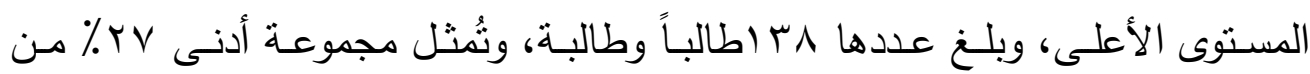

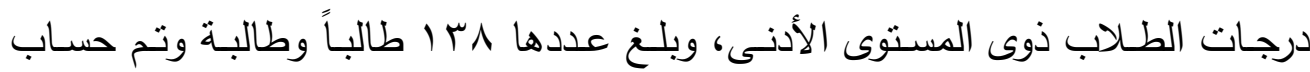
متوسطات درجات مجموعتى الطلاب فى كل مفردة من مفردات المقياس، وتم استخدام النسبة الحرجة Critical Ratio فى المقارنة بين متوسطات درجات مجموعتى الطلاب

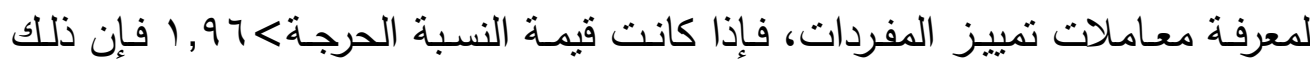
يُحدد لنا مستوى ثقة 90, •وشك مقداره 0 ., • فـى ضوء المساحات المعيارية، أما إذا

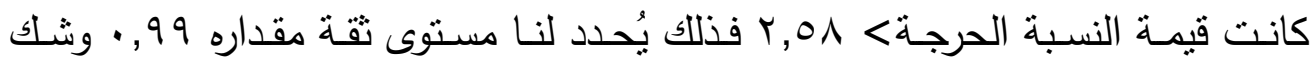
مقداره I +., فى ضوء المساحات المعيارية، ويؤكد ذلك أن الفرق القائم بين المتوسطين له دلالة إحصائية أكيدة ولا يرجع إلى الصدفة، أى أن هذه النسبة تميز تمييزاً واضحاً

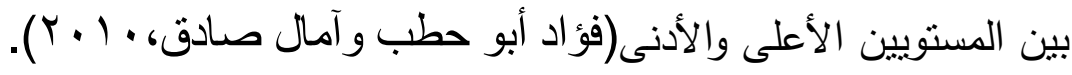


ويوضح جدول (V) معاملات النسبة الحرجة لمفردات مقياس المرونة العقلية.

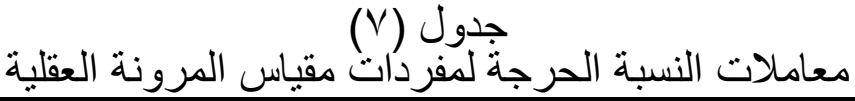

\begin{tabular}{|c|c|c|c|c|c|}
\hline \multicolumn{6}{|c|}{ البعد الأول } \\
\hline النسبة الحرجة & 5 & النسبة الحرجة & r t a t a & النسبة الحرجة & 5 \\
\hline${ }^{*} Y, V Y$ & ro & $\varepsilon, \cdot 9$ & $\sum\lceil$ & ${ }^{*}, \wedge 9$ & 09 \\
\hline${ }^{*} Y, T V$ & 00 & $T, Y T$ & 77 & $\overline{* \varepsilon, 1 \Gamma}$ & 19 \\
\hline${ }^{*}+, I V$ & $\varepsilon 0$ & ${ }^{*} \Gamma, \varepsilon 1$ & 10 & $\bar{*} r, \varepsilon$ & $\overline{r t}$ \\
\hline${ }^{*} r, \cdot V$ & 11 & $0,1 \pi$ & $\Lambda$ & $\varepsilon, Y V$ & rq \\
\hline${ }^{*} \varepsilon, I V$ & 70 & ${ }^{*} Y, V T$ & $\mathrm{~V}$ & FT, T乏 & ry \\
\hline \multicolumn{6}{|c|}{ تابع البعد الاول } \\
\hline النسبة الحرجة & $\begin{array}{l}5 \\
\end{array}$ & النسبة الحرجة & $\begin{array}{l}5 \\
5\end{array}$ & النسبة الحرجة & $\begin{array}{l}5 \\
5\end{array}$ \\
\hline$T, V I$ & $T$ & $T, T$ & $1 \varepsilon$ & $\Gamma, \lambda \varepsilon$ & 79 \\
\hline${ }^{*} Y, I V$ & $r$ & $\varepsilon, 1 \varepsilon$ & ro & ${ }^{*} Y, \wedge \Lambda$ & 07 \\
\hline & & & & $7,9$. & ह9 \\
\hline \multicolumn{6}{|c|}{ البعد الثانى } \\
\hline النسبة الحرجة & $\begin{array}{ll} \\
5\end{array}$ & النسبة الحرجة & $\begin{array}{ll}5 \\
5\end{array}$ & النسبة الحرجة & $\begin{array}{l}5 \\
5\end{array}$ \\
\hline$\varepsilon, O V$ & 0 & $T, 1 \varepsilon$ & $\overline{v e}$ & $\varepsilon, Y T$ & $\overline{T H}$ \\
\hline $7, Y$, & $\overline{T I T}$ & $\bar{T}, \Gamma V$ & $\overline{T V}$ & $0,1 \leqslant$ & $\overline{r \Lambda}$ \\
\hline$T, \cdot V$ & $\overline{r r}$ & $r, \wedge)$ & 0. & $\varepsilon, \wedge \Gamma$ & $\sum V$ \\
\hline$\varepsilon, \mu \nu$ & $\varepsilon r$ & $\varepsilon, \wedge \Gamma$ & $\varepsilon$ & $Y, V I$ & $T V$ \\
\hline$Y, V 7$ & זr & $r, 1 \varepsilon$ & 7. & T, YN & $r$. \\
\hline T, q1 & $7 \pi$ & $T, \cdot V$ & 9 & $0, \sum \Lambda$ & OV \\
\hline$\overline{F, Y V}$ & $\overline{V T}$ & $\varepsilon, I V$ & 17 & $\varepsilon, 7 \varepsilon$ & $\overline{\overline{T V}}$ \\
\hline & & & & $T, V \varepsilon$ & $\Gamma$. \\
\hline \multicolumn{6}{|c|}{ البعد التالث } \\
\hline النسبة الحرجة & $\begin{array}{l}5 \\
5\end{array}$ & النسبة الحرجة & $\begin{array}{l}5 \\
5\end{array}$ & النسبة الحرجة & r \\
\hline T, 19 & $1 T$ & T, 9. & 71 & $T, Y$ & $\overline{V I}$ \\
\hline$r, q 1$ & $V \Sigma$ & $\varepsilon, r V$ & $\overline{Y T}$ & $Y, \wedge \varepsilon$ & 01 \\
\hline$\varepsilon, Y V$ & $7 \varepsilon$ & $T, 1 \leq$ & ह1 & $T, r \Lambda$ & 71 \\
\hline$\varepsilon, \cdot 9$ & TI & $\varepsilon, \wedge \Gamma$ & 01 & $7, \pi$ & TA \\
\hline$r, 19$ & $\Gamma \xi$ & $r, V \lambda$ & IV & $0,1 \leq$ & Tा \\
\hline$\Gamma, \varepsilon)$ & $0 \leqslant$ & 0,9 & 1. & $r, \wedge 9$ & $\Gamma \wedge$ \\
\hline 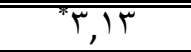 & $\varepsilon \leqslant$ & $\Gamma, \cdot \varepsilon$ & 7 & $F, Y Y$ & $\varepsilon \wedge$ \\
\hline
\end{tabular}

** دال عند مستوى 0 ., *

* دال عند مستوى 1 •, 
يتضح من الجدول السابق أنه توجد فروق دالة عند مستويي ا .,. - ـ ـ. • • بين متوسطات درجات مجموعتى الطلاب مرتفعى ومنخفضى المرونة العقلية ، فى عوامل المقياس لصالح الطلاب مرتفعى المرونة العقلية ، أى أن عوامل المقياس تميز تميزاً

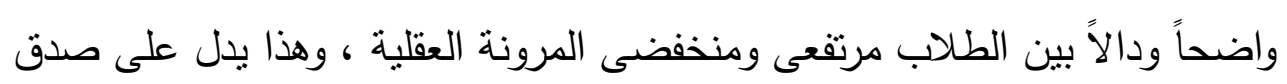
عوامل المقياس فى قياس ما وضعت لقياسه(المرونة العقلية). ب- ثبات مقياس المرونة العقلية

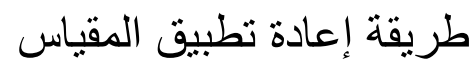
تم حساب ثبات مقياس المرونة العقلية بعد تطبيقه على العينة ( • اهم) طالباً وطالبة من طلاب كلية التربية والتربية النوعية وذلك بطريقة إعادة تطبيق الاختبار وبفاصل زمني قدره (IV) يوم من إجراء التطبيق الأول وتراوحت معاملات الارتباط بين التطبيق الأول

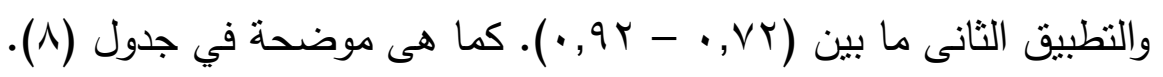

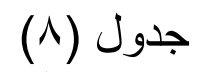

معاملات الثبات لمقياس المرونة العقلية بطريقة إعادة الاختبار ( ن = • به )

\begin{tabular}{|c|c|c|c|c|}
\hline الإختبار ككل & البعد الثالث & البعد الثاني & الأبعد & الأبعاد \\
\hline${ }^{*}, \wedge \varepsilon$ & ${ }^{*} \cdot, 9 r$ & ${ }^{*} \cdot, \vee \wedge$ & ${ }^{*} \cdot, V Y$ & معاملات الثبات \\
\hline
\end{tabular}

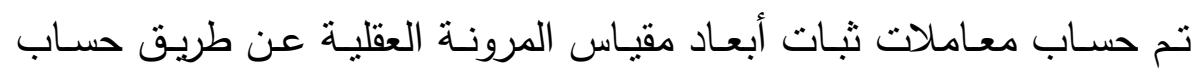

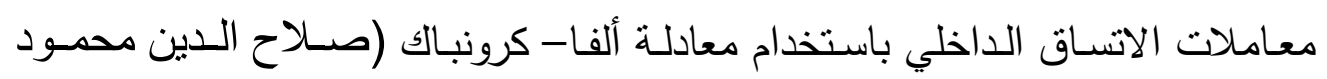
علام، • ( • ( ). وجدول (• ( ) يوضح معاملات ثبات الأبعاد الفرعية لمقياس المرونة العقلية باستخدام معامل ألفا- كرونباك.

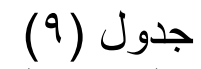

معاملات ثبات الأبعاد الفرعية لمقياس المرونة العقلية باستخدام معامل م (ن = • بro)

\begin{tabular}{|c|c|c|c|}
\hline البعد الثالث & البعد الثاني & البعد الاول & الأبعاد \\
\hline${ }^{*} \cdot, \mathrm{AV}$ & ${ }^{*} \cdot,{ }_{0}$ & $*, 79$ & معامل الثبات \\
\hline
\end{tabular}


الصورة النهائية للمقياس:

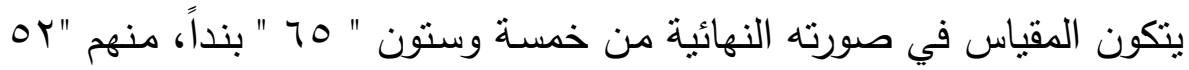

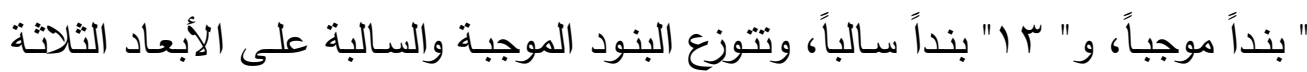

للمقياس كما يتضح من الجدول (• (1):

جدول (1) (1) (1)

توزيع بنود مقياس المرونة العقلية على الأبعاد الثناثة

\begin{tabular}{|c|c|c|c|c|}
\hline المئوية & كل البنود فيد & البنود المنتمية للبعد & البعد & 5 \\
\hline$r \mu,{ }_{\mu}$ & Tr & 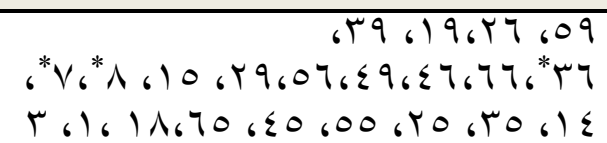 & المرونة الإدر اكية & 1 \\
\hline rr, & Tr & 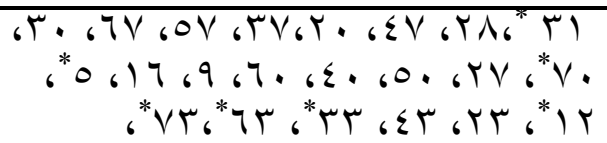 & المرونة التكيفية & r \\
\hline$T r, r)$ & Y) & 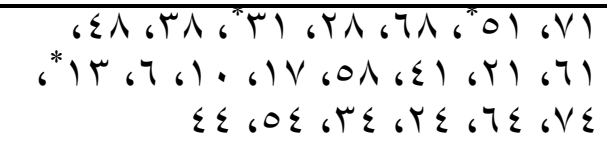 & المرونة التلقائية & $r$ \\
\hline$\% 1 \ldots$ & 70 & الاختبار ككل & & \\
\hline
\end{tabular}

* بنود سالبة.

تصحيح المقياس:

يتم تصحيح المقياس طبقاً لطريقة ليكرت LIKERT بحيث يختار الطالب بديل

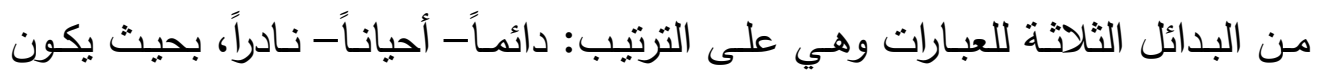

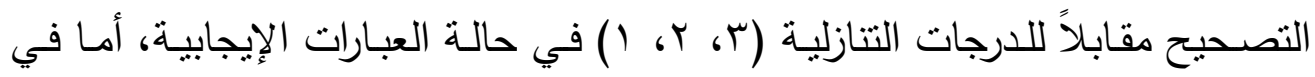

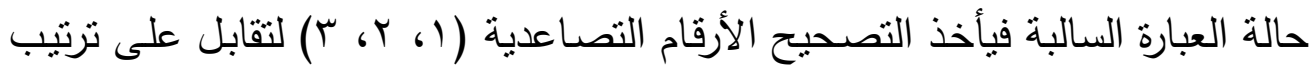

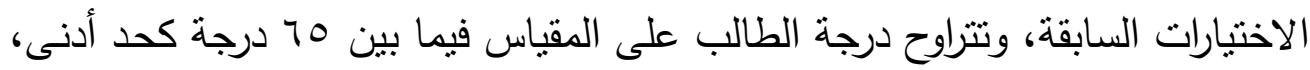

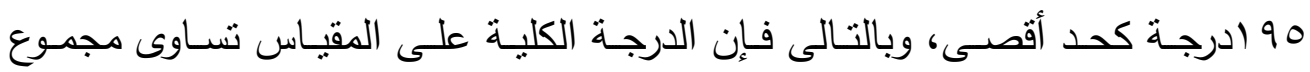
درجات الطالب فى أبعاد المقياس الثلاثة أو تساوى مجموع درجات الطالب على بنود المقياس( (7) وتُشير الدرجة المرتفعة على المقياس إلى تمتع الطالب بمرونة عقلية

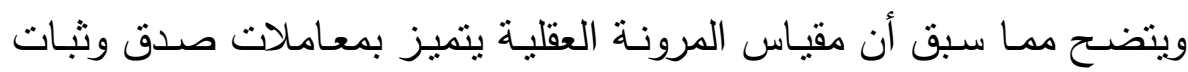




\section{المراجع}

صلاح الدين محمود علام(• ( • ( ). الأساليب الإحصائية الاستدلالية في تحليل بيانات

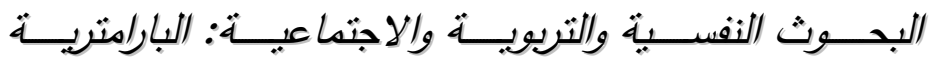

$$
\text { واللابارامتربية، طن، القاهرة، دار الفكر العربي. }
$$

صـلاح شريف عبد الوهاب(1) (1). المرونـة العقلية وعلاقتها بكل من منظور زمن اهن

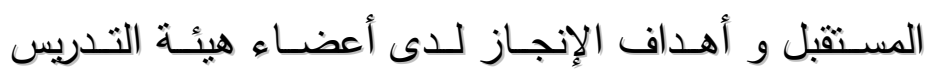
بالجامعـة، مجلـة بحوث التربية النوعية، جامعة المنصـورة،

$$
. V A-r \cdot{ }^{\prime} r \text {. }
$$

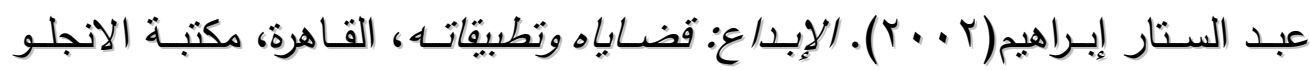
المصرية.

فؤاد أبو حطب وآمال صـادق( • ( + ). مناهج البحث وطرق التحلبل الإحصائي فى

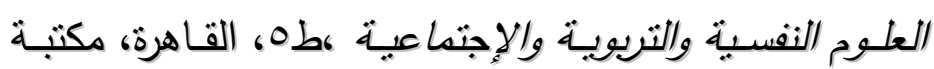
الأنجلو المصرية.

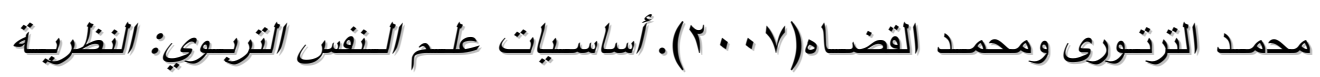
والتطبيق،عمان، دار الحامد للنشر والتوزيع.

Amy,N.Madewell.,; Elisabeth,Ponce-Garcia. (2016). Assessing resilience in emerging adulthood: The Resilience Scale (RS), Connor-Davidson Resilience Scale (CD-RISC), and Scale of Protective Factors (SPF), Personality and Individual Differences, 97(11),249255.

Virginie, Etienne.,; Claude Marin-Lamellet ; Bernard Laurent(2013). Mental flexibility Impairment In Student with early Alzheimer's disease: Asimulator-based Study , IATSS Research, 37(5), 16- 20.

Eagle,N., (2008). Behavioral Inference Across Cultures: Using Telephones as a Cultural Lens, IEEE Intelligent Systems, 23(4), 62-64. 
Shah,J,Y.,(2003). How Representations of Significant Others Implicitly, Automatic for the people: affect goal Pursuit, Journal of Personality and Social Psychology, 38(6),388-402.

Dibbets, P.,;Jolles,J.,(2006). The Switch Task for Children: Measuring

Mental Flexibility in Young Children, Journal Articles, Cognitive Development, 21(1), 60-71.

Ran,R.,(2009). Social Cognition, Automatic and Flexible, Nonconscious Goalpursuit Nonconscious,13 (1), 20-36.

Ran, Feng.,; Zhao-fang, Peng.,; Aa-hui Fan.,(2009). Social Cognition, Automatic and Flexible, Nonconscious Goalpursuit Nonconscious, 13 (1), 44-57.

William,S.,; Lisa, Iguchi.,(2013). Stress and Mental Flexibility In Autism Spectrum Disorders, North American Journal of Medical and Science, 6(3), 34-67.

Mc Nulty, Maryann., ; Mary., (2010). Living In the Global Village: Strategies For Teaching Mental Flexibility, Social Studies and The Young Learner,23(2), 21-24.

Bennett,J.,; Ulrich Müller., (2010). The Development of Flexibility and abstraction In Preschool Children, Merrill-Palmer Quarterly, 56(21), 455-473.

Olivia, Mobbs.,; Katia Lglesias.,; Martial Vander Linden.,(2011). Cognitive deficit In Obese Persons With and With out binge eating. Investigation Using a mental flexibility Task, Appetite, 57(1),263-271.

May, Tan.,(2005). Examining The Impact of an Outward Bound Singapore Program On The Life Effectiveness of Adolescents by University of New Hampshire, fromhttp://www.

citeseerx.ist.psu.edu/viewdoc/download?doi=10.1.1 $.535 .5812 \&$ rep $=$ rep $1 \&$ type.$p d f$

Cynthia,T. Matthew.,; Steven, E. Stemler.,(2013). Assessing Mental Flexibility With a new World recognition Test, Personality and Individual Differences, 55(8), 915920. 


\section{مقباس المرونة العقلية}

Mental flexibility Scale

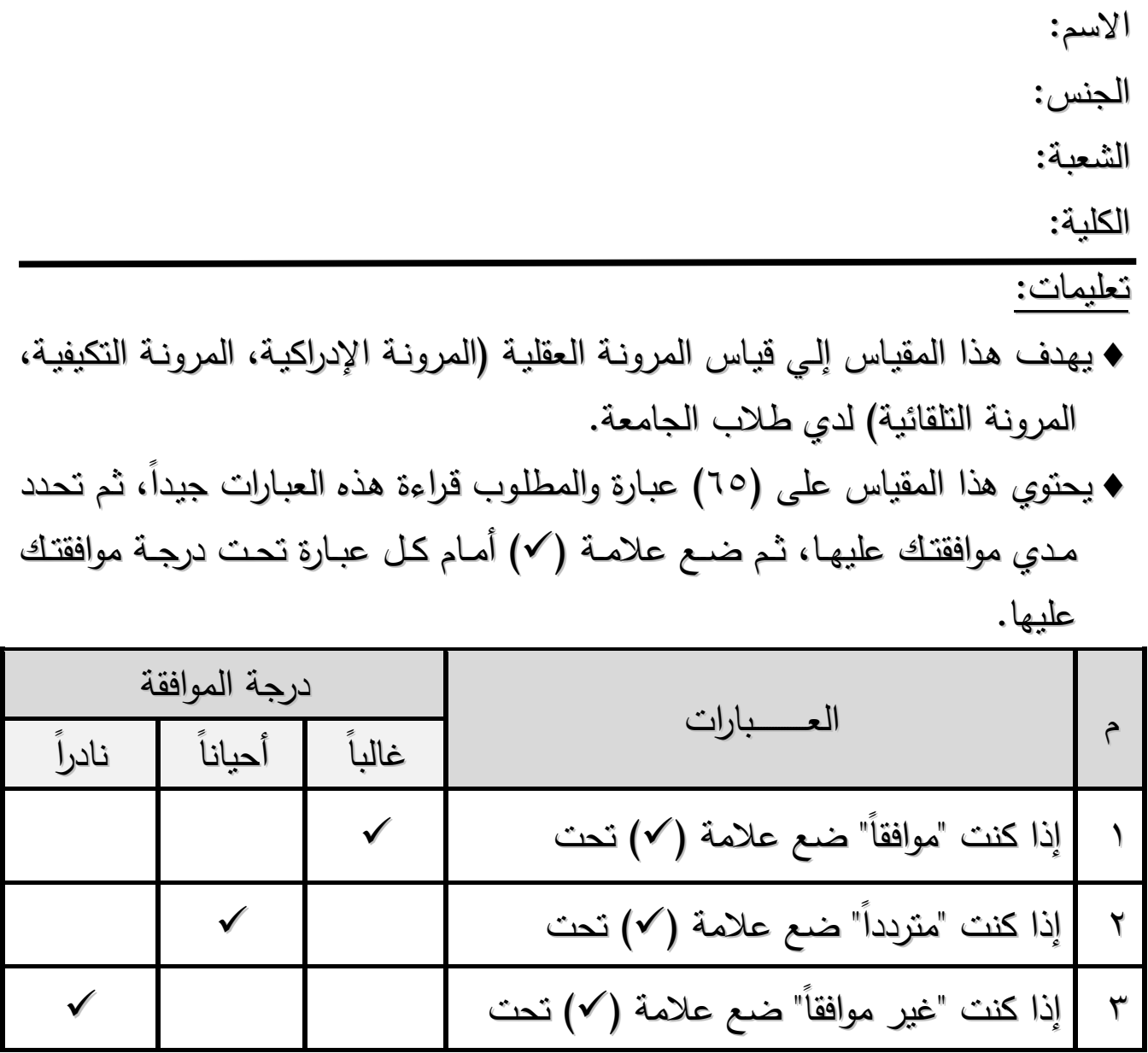

ملاحظات:

- - ليس هنالك وقت محدد للإجابة على عبارات الاستبيان.

- - نرجو أن تستجيب إلي كل عبارة من عبارات الاستبيان.

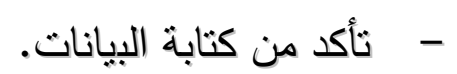

- - البيانات المرتبطة باستخدام هذا الاستييان سرية للغاية ولن نستخدم في أي أغراض سوي أغراض البحث.

كمئم الباحثة 


\begin{tabular}{|c|c|c|c|c|}
\hline 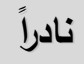 & أحياناً & غالباً & 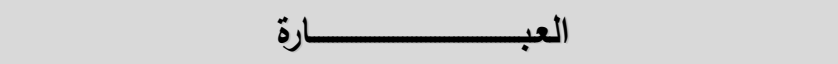 & r \\
\hline & & & أو سيئة. أصداماً على أفكارى ومفاهيمى سواء كانت جيدة & 1 \\
\hline & & & لدى حب استطلاع لمعرفة وإدراك ما حولى. & r \\
\hline & & & فيها. أراعى اختلاف المفـاهيم بـاختلاف السـياقات المسـتخدمة & r \\
\hline & & & اسامح واغفر لنفسى وللآخرين. & $\varepsilon$ \\
\hline & & & اتضايق من اختلاف الرأى حول قضية ما. & 0 \\
\hline & & & أقوم بتحليل المشكلة إلى عناصر بسيطة. & 7 \\
\hline & & & أعتقد أن متعـة الحيـاة وإثارتها تكمن فى قدرة الفرد على & V \\
\hline & & & لدى قدر على المثابرة حتى أنتهى مـن حل أى مشـكلة & $\Lambda$ \\
\hline & & & أرحب كثيراً بالمناقثات والحوار مع الآخرين. & 9 \\
\hline & & & أعتقد أن سوء الحظ يعود إلى سوء التخطبط. & 1. \\
\hline & & & اركز فقط فيما أفعله ولا شئُ أخر . & 11 \\
\hline & & & بُضايقنى جداً اللوم والعتاب حتى لوكنت استحقه. & Ir \\
\hline & & & لا بد أن أرد الإساءة مهما كانت العواقب. & Ir \\
\hline & & & أعتقد أن الثخص يستطيع بناء مستقبله بنفسه. & $1 \varepsilon$ \\
\hline & & & يُمكنى أن أنغاضى بسهولة عن أخطاء الآخرين. & 10 \\
\hline & & & أعتقد أن الفشل يعود إلى أسباب نكمن فى الشخص نفسه. & 17 \\
\hline & & & الاعتراف بالخطاُ أمر عسير بالنسبه لى. & IV \\
\hline & & & أسنطيع ثوجيه النقد لنفسى دون هدم. & 11 \\
\hline & & & أقوم بثقييم إنجازاتى الأسبوعية. & 19 \\
\hline
\end{tabular}




\begin{tabular}{|c|c|c|c|c|}
\hline 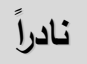 & أحياناً & غالباً & 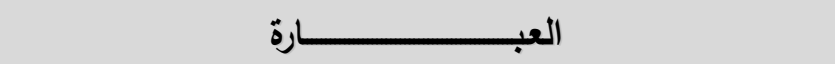 & b \\
\hline & & & قدرتى على تنفيذها. أضع خطى المستقبلية، غالباً ما أكون متأكداً من & r. \\
\hline & & & أحتـرم الآراء المتباينـة والمختلفـة عـن رأيسى عندـ مواجهـة & (1) \\
\hline & & & أثق فى قدراتى على التعامل مع المشاكل الصعبة. & rt \\
\hline & & & بسبب كثرة المشكلات لا أستطيع التخطيط للمستقبل. & r \\
\hline & & & أقبل التغيير والتعديل حسب كل موقف. & $r \leq$ \\
\hline & & & أبحث عن عدة طرق للتعامل مع المشكلات. & ro \\
\hline & & & مهما كانت العقبات فإننى أسنطيع تحقيق أهدافى. & ry \\
\hline & & & أخطط لمستقبل أفضل حتى فى الأوقات القاسية. & rV \\
\hline & & & بعدة طرق مواجهة صعتوبة فى تحقيق الأهداف، احاول انجازها & rA \\
\hline & & & أستطيع التغلب على المصائب مهما كانت. & rq \\
\hline & & & أستطيع التكيف مع التغييرات المستحدثة. & r. \\
\hline & & & أشنعر بعدم السبطرة على الأشياء المهمة فى حياتى. & r \\
\hline & & & تُداهمنى الضـغوط فى الجامعة نظراً لجمودى الذهنى فى & rt \\
\hline & & & أُغير قيمى ومبادئى إذا دعت الظروف لذلك. & rr \\
\hline & & & أستعيد نوازنى بسرعة بعد الأوقات الصعبة. & $r \varepsilon$ \\
\hline & & & أتجنب المواقف التى تجعلنى جامد ذهنياً. & ro \\
\hline & & & أنجنب القيام بالأثياء عند الثعور بالخطر . & די \\
\hline & & & على الإنسان أن يُغير أساليبه حنى يصل إلى الهدف. & rv \\
\hline & & & لا أنغلب على المشكلات عند ثراكمها. & rᄉ \\
\hline
\end{tabular}




\begin{tabular}{|c|c|c|c|c|}
\hline 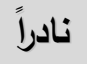 & أحياناً & غالباً & 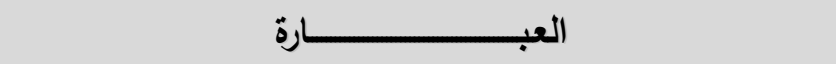 & م \\
\hline & & & أشعر بالخوف من مواجهة المشكلات حتى قبل أن تحدث. & rq \\
\hline & & & يُمكننـى نطويـع الفكـرة لكى تنتاسـب مـع الموقف الـذى & $\varepsilon$ \\
\hline & & & أستطيع التكيف مع المشكلات الحياتية. & 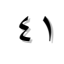 \\
\hline & & & أستعين بالآخرين فى حل المشاكل التى تواجهنى. & $\varepsilon r$ \\
\hline & & & أنشعر بالرهبة والخوف عند التعرض لمواقف جديدة. & $\varepsilon r$ \\
\hline & & & 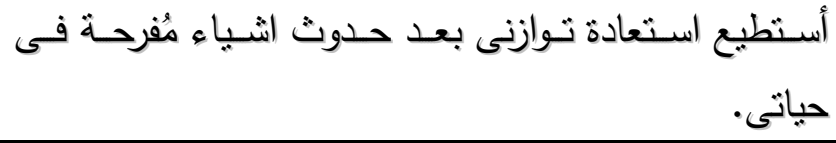 & $\leqslant \varepsilon$ \\
\hline & & & أحاول إعطاء دلائل كثيرة لآرائى ومعثقداتى. & $\leqslant 0$ \\
\hline & & & آخر. اهنـامى بنفسى لا يترك لـى فرصـة للتفكير في أى شـئ & $\leqslant 7$ \\
\hline & & & 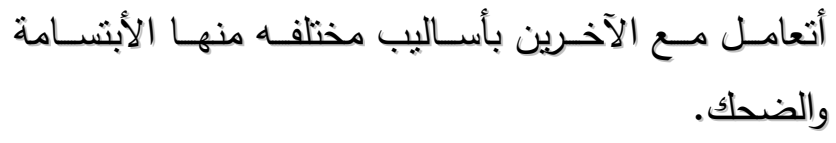 & $\leqslant V$ \\
\hline & & & الأفكار . عـن التجـارب الحياتيــة لأنهـا نُكسـنى تتوعـاً فـى & $\varepsilon \wedge$ \\
\hline & & & الحياة الثابتة هى الحياة الممتعة بالنسبة لى. & $\leqslant 9$ \\
\hline & & & لا أقيد أفكارى تحت إطار محدد أثناء مواجهتى للمشكلة. & 0. \\
\hline & & & تخرجنى من الجمود الفكرى. تــوع الأفكار حـول المواقـف التـى تـواجهنى & 01 \\
\hline & & & ذلا أمسانع فى تكرار محاولاتى لحل مشكلة ما مهما كلفنى & or \\
\hline & & & يُسهم فى حلها. أستخدم الأفكار غير التقليدية فى مواجهة مشكلة ما طالما & or \\
\hline
\end{tabular}




\begin{tabular}{|c|c|c|c|c|}
\hline 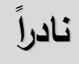 & أحياناً & غالباً & 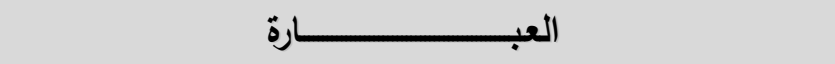 & م \\
\hline & & & أحاول انجاز المهمات بأكثر من طريقة مختلفة. & os \\
\hline & & & أضع جميع الإحتمالات فى حل المشكلة وأختار انسبها. & 00 \\
\hline & & & كانت أفكار غريبة. مـن إنتاج الأفكار حـول موضـوع مـا، حتى ولـو & 07 \\
\hline & & & عند مشاركة إلى إنتاج أكبر قدر من الأفكار حول موضوع ما & ov \\
\hline & & & والأحساول الإنتبـاه إلـى المجموعـات المتتوعـة مـن الرســائل & $0 \wedge$ \\
\hline & & & أنظر إلى الأمور بمنظور ثابت وواحد . & 09 \\
\hline & & & أبثعد عن الأشخاص الذين لا يرون غير آرائهم فى حل & 7. \\
\hline & & & أبحث عن حلول مختلفة عند مواجهة المشكلات. & 71 \\
\hline & & & أنطرق بذهنى لأفكار غريبة ومستحيله لعلاج المشكلة. & 74 \\
\hline & & & أستخدم فى حديثى كلمات مرنة وليست قاطعة. & r \\
\hline & & & السلوك. من السـهل التقكير فى طرق جديدة وغير نقلبديـة لتعديل & $7 \varepsilon$ \\
\hline & & & أتخطى العقبات بكل سهولة من خلال أفكارى المنتوعة. & 70 \\
\hline
\end{tabular}

